CRIPPS AW \& OTCZYK DC. Prospects for a vaCCine against otitis media.

Invited Review. Expert Review of Vaccines. 2006;5(4):517-534.

Review

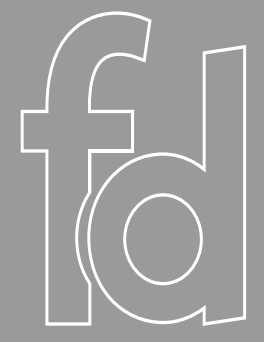

\title{
Prospects for a vaccine against otitis media
}

\author{
Allan W Cripps ${ }^{\dagger}$ and Diana COtczyk
}

Otitis media

Pathogenesis of OM

Preventative strategies

Models of vaccine efficacy

Viral vaccines

Bacterial vaccines

Immunization against NTHi

AOM

Pneumococcal protein

antigens

NTHi vaccine candidates

$M$. catarrhalis vaccine

candidates

Expert commentary

Five-year view

References

Websites

Affiliations

\section{KEYWORDS:}

animal models, antigens,

children, Haemophilus influenzae,

infants, influenza, Moraxella

catarrhalis, nontypeable, otitis

media, parainfluenza, respiratory

syncytial virus, Streptococcus

pneumoniae, vaccination

\author{
Allan Whipps and Diana COtczyk
}

Otitis media is a major cause of morbidity in $80 \%$ of all children less than 3 years of age and often goes undiagnosed in the general population. There is evidence to suggest that the incidence of otitis media is increasing. The major cause of otitis media is infection of the middle ear with microbes from the nasopharynx. The anatomical orientation of the eustachian tube, in association with a number of risk factors, predisposes infants and young children to the infection. Bacteria are responsible for approximately $70 \%$ of cases of acute otitis media, with Streptococcus pneumoniae, nontypeable Haemophilus influenzae and Moraxella catarrhalis predominating as the causative agents. The respiratory viruses, respiratory syncytial virus, rhinovirus, parainfluenza and influenza, account for $30 \%$ of acute otitis media cases. Over the past decade, there has been a profound increase in the reported resistance to antibiotics, which, with increased disease burden, has focussed attention on vaccine development for otitis media. A polymicrobial formulation containing antigens from all major pathogens would have the greatest potential to deliver a sustained reduction in the disease burden globally. The disappointing outcomes for otitis media seen with the polysaccharide pneumococcal conjugate vaccine have raised major challenges for the vaccination strategy. Clearly, more knowledge is required concerning immune mechanisms in the middle ear, as well as vaccine formulations containing antigens that are more representative of the polymicrobial nature of the disease. Antigens that have been extensively tested in animal models are now available for testing in human subjects.

Expert Rev. Vaccines 5(4), xxx-xxx (2006)

Otitis media $(\mathrm{OM})$ is an infectious disease of the young, commonly affecting more than three-quarters of all children before they reach 3 years of age [1]. OM, which can be caused by a variety of etiological agents, including nontypeable Haemophilus influenzae (NTHi), Streptococcus pneumoniae, Moraxella catarrhalis, respiratory syncytial virus (RSV), rhinovirus, parainfluenza (PIV) and influenza is responsible for significant morbidity. Some $5 \%$ of children are predisposed to recurrent episodes of OM that is associated with repeated courses of antibiotics, the need for general surgery for tympanostomy tube placement, hearing impairment and long-term effects on speech and language development that lead to learning and behavioural difficulties as these children reach school age [2-4]. Although OM has a low associated mortality in the developed world, its high prevalence globally in infants and children makes $\mathrm{OM}$ a significant burden to patients, caregivers and the healthcare system. It is the primary reason for preschool children to visit a general practitioner, accounting for 16 million visits in 2000 [5] and responsible for over half of the antibiotics dispensed to children under 3 years of age in the USA [6]. In 2005, it was estimated that the national cost of acute otitis media (AOM) in the USA was between US $\$ 3.8$ billion and 5.7 billion; $40 \%$ of national expenditure for $\mathrm{OM}$ is generated by children 1-3 years of age whilst two-thirds of the total cost is attributable to chronic ear infections progressing from AOM [7]. Over a period of 10-20 years, there has been a reported 68\% increase in OM incidence in a population-based study in Finland [8] and a $15 \%$ increase in the reported incidence of OM 
in children in the USA [9]. A rising trend in OM has also been observed in Australia over the last 30 years, with OM progressing from being the fourth most frequent problem managed by general practitioners in 1971 to the third most frequent problem in 2001 [10].

In the last decade, resistance to one or more antimicrobials has escalated dramatically, largely due to the overuse of antibiotics [11]. The indiscriminate use of antibiotics in poorly diagnosed cases of AOM and the use of multiple courses of antibiotics in difficult to treat cases of OM have promoted the selection and spread of resistant bacteria. Treatment of OM caused by antibiotic-resistant pathogens often requires the use of more expensive and potentially more toxic drugs, perpetuating a vicious cycle of inadequate management, culminating in an increased number of infections with a decreased response to commonly used antibiotics, and sometimes treatment failure. The increased number of treatment failures [12] associated with inadequate coverage of the implicated pathogens may be the result of the shift in OM microbiology in the pediatric population following the introduction of pneumococcal vaccination [13]. There has been an observed increase in $\beta$-lactamase-producing $H$. influenzae and a decrease in resistant $S$. pneumoniae in the USA [13], initiating a guideline recommendation for high-dose amoxicillin/clavulate for the treatment of AOM in patients who have failed previous treatment with amoxicillin [14].

In order to break this cycle, it is necessary to favor the prevention of OM rather than its treatment. Attention has been focused on developing a more effective vaccine against some of the pathogens responsible for middle-ear disease as a long-term strategy to reduce both antibiotic dependence and disease burden.

\section{Otitis media}

Despite the existence of precise clinical definitions, the diagnosis and management of AOM have generated considerable debate and differences in opinion amongst health professionals [15-17]. $\mathrm{AOM}$ is defined as the presence of middle-ear effusion accompanied by signs and symptoms of acute infection [18]. Otitis media with effusion (OME) is defined as a condition of inflammation of the middle ear with fluid collection in the middle-ear space. The signs and symptoms of acute infection are not present and the tympanic membrane is not perforated [19]. There is often a clinical continuum between AOM and OME. It is important to discriminate between the two conditions because OME is usually not treated with antimicrobials. Persistent middle-ear fluid (MEF) results in decreased mobility of the tympanic membrane and serves as a barrier to sound conduction and consequently hearing loss.

\section{Acute otitis media}

Almost two-thirds (62\%) of children have had at least one episode of AOM by 1 year of age and approximately $80 \%$ by 3 years of age, with a peak incidence between 6 and 18 months [1]. At least $80 \%$ of $\mathrm{AOM}$ cases resolve within 2-14 days and with minimal benefits from antimicrobials [20]. The 'Clinical Practice Guideline: Diagnosis and Management of Acute Otitis
Media' recommends analgesia for the management of AOM for children older than 2 years fo age, with the introduction of antibiotics if the child deteriorates or is not improving within 48-72 h [18]. In severe cases of certain diagnosis, antibacterial therapy is recommended. There is no consensus for the observation period prior to antibiotic treatment for children younger than 2 years of age with a recommendation for immediate treatment on clinical considerations along with certainty of diagnosis. Judicious use of antibiotics is recommended with the global prevalence of antibiotic-resistant bacteria and the increased risk of carriage of potential respiratory pathogens [21].

\section{Recurrent AOM}

Recurrent AOM is defined as three or more episodes within a 6-month period, or four or more episodes within a 12-month period. It commonly affects $10-20 \%$ of children by 12 months of age with approximately $40 \%$ of 7 -year olds having experienced six or more episodes of AOM [22]. The natural history of AOM is for the number of infections to decrease with time; however, some very young children may have a propensity for AOM, in which case it may be necessary to have tympanostomy tubes inserted.

\section{Otitis media with effusion}

More than half of children have experienced OME by 1 year of age. Recurrent OME occurs in 30-40\% of children and 5-10\% of episodes last 1 year or longer [23]. The extensive literature on the role of antibiotics in the management of OME suggests a benefit that is short-lived [24]. For those children with effusions persisting for more than 3 months who have an increased risk for developmental difficulties, surgical intervention should be considered [19].

\section{Pathogenesis of OM Etiology}

The causes and pathogenesis of OM are multifactorial [25]; however, paramount to the disease process is a dysfunctional eustachian tube that potentially favors $O M$ in infants and young children. High rates of nasopharyngeal colonization with potentially pathogenic bacteria and viruses [26], socio-economic status and repeated exposure to large numbers of children whether at home or in childcare [27] are reported to be the most significant.

\section{Microbiology}

Bacterial and viral infections are the single most important cause of OM. A viral upper respiratory tract infection may modify or overwhelm the protective mechanisms of the mucosal membranes and initiate the cascade of events that lead to bacterial pathogens gaining access to the usually sterile environment in and around the middle-ear [28]. Bacteria are isolated in approximately $70 \%$ of MEF samples from children with OM [28]. Three microbes are reported to predominate as the cause of AOM: S. pneumoniae (25-50\%), NTHi (15-30\%) and M. catarrhalis (3-20\%) [29]. Colonization of the nasopharynx with these 
microbes at an early age and the early onset of OM are closely correlated [26,30]. The true indication of bacterial involvement in OM may be underestimated as PCR-based assay systems detect the presence of bacterial DNA in up to $80 \%$ of culturally sterile MEFs [31-33].

In a review of the importance of respiratory viruses in $A O M$, it has been reported that respiratory viruses alone account for $30 \%$ of AOM cases or with concurrent bacterial pathogens in approximately $15 \%$ of cases [28]. RSV is the most commonly detected virus in MEF. Other viral agents include rhinovirus, influenza virus and PIV. Enterovirus and adenovirus are also reported occasionally. Using conventional viral culture and viral antigen detection, the same viruses have been identified in nasopharyngeal aspirates from children with AOM. When sensitive techniques such as PCR are used, rhinovirus has also been found to be as common as RSV [34], and interestingly, has been associated with an increase in antibiotic failure in the treatment of $\mathrm{AOM}$ when co-infecting with bacteria [35]. The PCR assay has substantially increased the detection of viruses with a threefold increase in sensitivity compared with viral culture [36]. This has allowed a broader range of viruses to be detected in MEF samples from children with AOM [37], and indeed has enabled the detection of the newly discovered human respiratory pathogens metapneumovirus (hMPV), which has been implicated in OM [38] and coronavirus (HCoV-NL63) [39]. PCR used in a retrospective study of nasal washings collected over a 20 -year period detected $\mathrm{hMPV}$ in $5 \%$ of specimens from children with upper respiratory infections who had previously tested culture-negative for viruses. $\mathrm{AOM}$ was found in $50 \%$ of these children. hMPV was detected at a similar frequency to other viral middle-ear pathogens [40].

\section{Immunology}

Host defense mechanisms in the middle ear associated with $\mathrm{OM}$ are poorly understood. Animal studies have shown that the middle-ear cavity and eustachian tube have immune characteristics similar to other mucosal sites [41,42]. This suggests that the induction of a mucosal immune response may be most relevant in providing protection against infectious agents that cause OM. In adult human subjects it is known that mucosal immune competence may be down-regulated by persistent nasopharyngeal carriage [43] or neonatal colonization [CRIPPS ETAL; KALGOORLIE OM PROJECT, UNPUBLISHED DATA] and this down regulation may be antigen specific, shifting the host-parasite relationship in favor of higher levels of bacterial colonization in the nasopharynx, a major risk factor for OM $[44,45]$. Other studies have suggested a number of subtle systemic immunodeficiencies that are associated with proneness to $\mathrm{OM}$, but none of these are conclusive to causal linkage. More recently, genetically determined functional polymorphisms observed in both leukocyte $\mathrm{Fc} \gamma$ and mannose-binding lectins suggest that these warrant further study with respect to disease susceptibility [46]. Clearly further studies are needed in order to determine the relationship between mucosal immune competence, nasopharyngeal colonization, MEF inflammatory and immunological parameters, and OM.

\section{Preventative strategies The surgical approach}

The 'Clinical Practice Guidelines' recommend that surgical intervention should only be performed on children with OME lasting 4 months or more with persistent hearing loss and other signs and symptoms, for recurrent or persistent OME in children at risk regardless of hearing status, or when there has been structural damage to the tympanic membrane or middle ear [19]. Tympanosotomy tube insertion is the treatment of choice followed by adenoidectomy. Both procedures have been demonstrated to reduce OME prevalence. However, outcomes from surgery are highly variable and given that the benefits are short-term $(20-50 \%$ of OME cases relapse after tube extrusion) [19], the implications of surgery and the sequelae of indwelling tubes $(7 \%$ of cases experience recurrent otorrhea or obstruction) and long-term sequelae after tube extrusion, including tympanosclerosis (32\%), must be considered [47].

\section{Vaccination approach}

$\mathrm{OM}$ is a polymicrobial disease and as such, any vaccine should target the primary infectious pathogens $S$. pneumoniae, NTHi, M. catarrhalis, RSV, rhinovirus, PIV and influenza, and also protect infants from 2 months of age. Ideally, it should target the two levels of OM development: the viral destruction of the respiratory tract epithelium and the multiplication of bacteria in the middle ear. The feasibility of producing a vaccine that is capable of protecting against all OM pathogens is doubtful; nevertheless, a combined bacterial-viral vaccine formulation for OM should be the long-term objective. For now, the general consensus is that an effective $\mathrm{OM}$ vaccine will need to contain antigens that induce a protective response in the middle ear against all three of the most common infecting bacteria. Although this may not provide unequivocal protection against $\mathrm{OM}$, because of the high frequency of bacterial OM, the actual numbers of episodes prevented by this vaccine could be substantial. Strong rationale would suggest that preventing $\mathrm{OM}$ in the first year of life with an effective treatment for $\mathrm{AOM}$ and the prevention of subsequent infection could have a significant human and economic impact. Universal vaccination would be the optimum outcome due to the universal nature of the disease and the difficulty in assessing those children who are predisposed to recurrent OM. This could be achieved by incorporating the $\mathrm{OM}$ vaccine into the national immunization schedules where appropriate.

The challenge is to identify the appropriate antigens, namely those antigens able to generate an appropriate immune response to prevent disease, which are also conserved among strains, and present them in such a way as to generate a protective immune response in infants and young children without causing immune-mediated damage to the middle ear. TABLE 1 lists many of these antigens, and summarizes the current status of vaccine research and development.

The nasopharynx is colonized by a broad variety of microorganisms, including commensal bacteria, as well as potential pathogens such as $S$. pneumoniae, NTHi and M. catarrhalis. The concern arises that in such a finely tuned ecological environment an 
Table 1. Summary of vaccines and vaccine candidate antigens for bacterial otitis media.

\begin{tabular}{|c|c|c|c|c|c|c|}
\hline Bacteria & Vaccine & Manufacturer & $\begin{array}{l}\text { Stage of } \\
\text { development }\end{array}$ & $\begin{array}{l}\text { Opsonizing or } \\
\text { bactericidal } \\
\text { antibody } \\
\text { detected }\end{array}$ & $\begin{array}{l}\text { Protection } \\
\text { demonstrated in } \\
\text { an animal model } \\
\text { of OM }\end{array}$ & $\begin{array}{l}\text { Protection } \\
\text { demonstrated in } \\
\text { human subjects } \\
\text { against OM }\end{array}$ \\
\hline \multicolumn{7}{|c|}{ Streptococcus pneumoniae } \\
\hline & Pneumovax $23^{\mathrm{TM}}$ & Aventis Pasteur & Licensed & & & $\begin{array}{l}\text { No - children as a } \\
\text { booster }\end{array}$ \\
\hline & Prevenar $^{\mathrm{TM}}$ & Wyeth-Lederle & Licensed & & & $\begin{array}{l}\text { Yes - infants, } \\
\text { children }\end{array}$ \\
\hline & $\begin{array}{l}\text { Glyconjugate } \\
\text { vaccine }(4,6 \mathrm{~B}, 9 \mathrm{~V}, \\
14,18 \mathrm{C}, 19 \mathrm{~F}, 23 \mathrm{~F}) \\
\text { conjugated to } \\
\text { meningococcal B } \\
\text { OMP }\end{array}$ & Merck & Phase III & & & Yes - infants \\
\hline & $\begin{array}{l}\text { Glyconjugate } \\
\text { vaccine }(1,4,5,6 \mathrm{~B}, \\
9 \mathrm{~V}, 14,18 \mathrm{C}, 19 \mathrm{~F}, \\
23 \mathrm{~F}) \text { conjugated to } \\
\text { CRM197 }\end{array}$ & Wyeth-Lederle & Phase III & & & $\begin{array}{l}\text { Yes - infants, } \\
\text { toddlers }\end{array}$ \\
\hline & $\begin{array}{l}\text { Glyconjugate } \\
\text { vaccine }(1,4,5,7 \mathrm{~F}, \\
9 \mathrm{~V}, 19 \mathrm{~F}, 23 \mathrm{~F}) \\
\text { conjugated to } \\
\text { tetanus protein } \\
\text { and }(3,6 \mathrm{~B}, 14 \text { and } \\
\text { 18C) conjugated } \\
\text { to diphtheria } \\
\text { toxoid }\end{array}$ & Aventis Pasteur & Phase II & & & Yes - infants \\
\hline & $\begin{array}{l}\text { Glyconjugate } \\
\text { vaccine }(1,3,4,5, \\
6 B, 7 F, 9 V, 14,18 C, \\
19 F, 23 F) \\
\text { conjugated to } \\
H . \text { influenzae- } \\
\text { derived protein D }\end{array}$ & GlaxoSmithKline & Phase III & & & Yes - infants \\
\hline & $\begin{array}{l}\text { Glyconjugate } \\
\text { vaccine }(1,3,4,5 \text {, } \\
6 \mathrm{~A}, 6 \mathrm{~B}, 7 \mathrm{~F}, 9 \mathrm{~V}, 14, \\
18 \mathrm{C}, 19 \mathrm{~A}, 19 \mathrm{~F}, 23 \mathrm{~F}) \\
\text { conjugated to } \\
\text { CRM197 }\end{array}$ & Wyeth-Lederle & Phase $\mid / \|$ & - & - & - \\
\hline & PspA & Aventis Pasteur & Preclinical & - & Yes & - \\
\hline & PsaA & Aventis Pasteur & Preclinical & - & - & - \\
\hline & $\begin{array}{l}\text { PspA }+ \text { PsaA }+ \\
P d B\end{array}$ & & Preclinical & - & - & - \\
\hline & Neuraminidase & & Preclinical & - & Yes & - \\
\hline & BVH-3 \& BVH-11 & GlaxoSmithKline & Phase I & Yes & - & - \\
\hline
\end{tabular}


Table 1. Summary of vaccines and vaccine candidate antigens for bacterial otitis media.

\begin{tabular}{|c|c|c|c|c|c|c|}
\hline Bacteria & Vaccine & Manufacturer & $\begin{array}{l}\text { Stage of } \\
\text { development }\end{array}$ & $\begin{array}{l}\text { Opsonizing or } \\
\text { bactericidal } \\
\text { antibody } \\
\text { detected }\end{array}$ & $\begin{array}{l}\text { Protection } \\
\text { demonstrated in } \\
\text { an animal model } \\
\text { of } \mathrm{OM}\end{array}$ & $\begin{array}{l}\text { Protection } \\
\text { demonstrated in } \\
\text { human subjects } \\
\text { against OM }\end{array}$ \\
\hline \multicolumn{7}{|c|}{ Haemophilus influenzae (nontypeable) } \\
\hline & $\begin{array}{l}\text { Glyconjugate } \\
\text { vaccine }(1,3,4,5, \\
6 \mathrm{~B}, 7 \mathrm{~F}, 9 \mathrm{~V}, 14,18 \mathrm{C}, \\
19 \mathrm{~F}, 23 \mathrm{~F}) \\
\text { conjugated to } \\
\text { H. influenzae- } \\
\text { derived protein D }\end{array}$ & GlaxoSmithKline & Phase III & & & Yes - infants \\
\hline & $\begin{array}{l}\text { Subunit detoxified } \\
\text { LOS conjugated to } \\
\pi\end{array}$ & & Phase I & Yes & Yes & - \\
\hline & $\begin{array}{l}\text { Subunit detoxified } \\
\text { LOS conjugated to } \\
\text { HMW protein } \\
\text { from H. influenzae } \\
\text { (nontypeable) }\end{array}$ & & Preclinical & Yes & Yes & - \\
\hline & OMP P6 & & Preclinical & Yes & Yes & - \\
\hline & $\begin{array}{l}\text { Recombinant P6 } \\
\text { protein } \\
\text { conjugated to } \\
\text { adamantlyamide } \\
\text { dipeptide }\end{array}$ & & Preclinical & - & Yes & - \\
\hline & $\begin{array}{l}\text { Recombinant P6 } \\
\text { protein } \\
\text { conjugated to } \\
\text { cholera toxin }\end{array}$ & & Preclinical & - & - & - \\
\hline & OMP 26 & & Preclinical & - & Yes & - \\
\hline & $\begin{array}{l}\text { OMP P5-derived } \\
\text { peptides }\end{array}$ & & Preclinical & - & Yes & - \\
\hline & OMP P2 subunit & & Preclinical & Yes & - & - \\
\hline & OMPP1 & & Preclinical & Yes & Yes & - \\
\hline & OMP Hin47 & Aventis Pasteur & Phase I & - & Yes & - \\
\hline & HMW1/HMW2 & & Preclinical & Yes & Yes & - \\
\hline & $\begin{array}{l}\text { Hap conjugated to } \\
\text { mutant cholera } \\
\text { toxin }\end{array}$ & & Preclinical & - & Yes & - \\
\hline & Recombinant Hap & & Preclinical & - & Yes & - \\
\hline & $\begin{array}{l}\text { Nonenzymatically } \\
\text { active rP4 }\end{array}$ & & Preclinical & Yes & - & - \\
\hline \multicolumn{7}{|c|}{ Moraxella catarrhalis } \\
\hline & $\begin{array}{l}\text { Adherence } \\
\text { proteins UspA1, } \\
\text { CD, MID, Mcap }\end{array}$ & & Preclinical & Yes - UspA and CD & - & - \\
\hline & $\begin{array}{l}\text { Protein involved in } \\
\text { hemagglutination } \\
\text { Hag }\end{array}$ & & $R$ \& $D$ & - & - & - \\
\hline
\end{tabular}


Table 1. Summary of vaccines and vaccine candidate antigens for bacterial otitis media.

\begin{tabular}{|c|c|c|c|c|c|c|}
\hline Bacteria & Vaccine & Manufacturer & $\begin{array}{l}\text { Stage of } \\
\text { development }\end{array}$ & $\begin{array}{l}\text { Opsonizing or } \\
\text { bactericidal } \\
\text { antibody } \\
\text { detected }\end{array}$ & $\begin{array}{l}\text { Protection } \\
\text { demonstrated in } \\
\text { an animal model } \\
\text { of OM }\end{array}$ & $\begin{array}{l}\text { Protection } \\
\text { demonstrated in } \\
\text { human subjects } \\
\text { against OM }\end{array}$ \\
\hline & $\begin{array}{l}\text { Proteins involved } \\
\text { in iron acquisition } \\
\text { LbpA/LbpB, } \\
\text { TbpA/TbpB, CopB, } \\
\text { B1 }\end{array}$ & & Preclinical & $\begin{array}{l}\text { Yes - TbpB and } \\
\text { CopB }\end{array}$ & - & - \\
\hline & $\begin{array}{l}\text { Protein involved in } \\
\text { serum resistance } \\
\text { UspA2 }\end{array}$ & & Preclinical & Yes & - & - \\
\hline & $\begin{array}{l}\text { Protein involved in } \\
\text { phase variation } \\
\text { UspA } 1 / 2\end{array}$ & & $R \& D$ & - & & - \\
\hline & $\begin{array}{l}\text { Highly conserved } \\
\text { proteins } E, C D, G 1\end{array}$ & & $R \& D$ & - & & - \\
\hline & $\begin{array}{l}\text { Detoxified LOS } \\
\text { conjugated to } \\
\text { either TT or CRM }\end{array}$ & & Preclinical & Yes & - & - \\
\hline
\end{tabular}

external force, such as vaccination, may unfavorably influence colonization and/or elimination of microorganisms creating a niche for new pathogens to colonize the nasopharynx. A notable example is the accumulating evidence suggesting that the use of pneumococcal vaccines may be exerting a selective pressure to perpetuate the emergence of penicillin resistance and multiple antibiotic resistance among nonvaccine serotypes in the nasopharynges of the pediatric population [48-50]. Several studies have demonstrated an increase in nasopharyngeal carriage by nonvaccine pneumococci among vaccinated children [51-56]. The increase in carriage of nonvaccine serotypes may represent a replacement of serotypes or the unmasking of resident nonvaccine serotypes. Currently, antimicrobial resistance is identified predominantly among serotypes included in the conjugate vaccine; of concern is the possibility that capsular transformation may serve as a mechanism for spreading antibiotic resistance to nonvaccine serotypes [57]. The appearance and increased prevalence of nonvaccine variants of major antibiotic-nonsusceptible clones [57] may have significant implications in middle-ear disease with the observation that the nonvaccine strains may be as virulent as the vaccine strains and capable of causing AOM [52,56,58]. In a trial of a conjugate vaccine in Finland [56], there were $33 \%$ more episodes of AOM in the vaccine group caused by nonvaccine serotypes than in the control group after the booster dose of vaccine. The potential implications for the risk of pneumococcal disease would be that, without intervention, another group of serotypes would become established over time, diminishing the efficacy of the vaccine. Pneumococcal vaccination may also induce replacement by other potential pathogens, such as Staphylococcus aureus [59,60], Streptococcus pyogenes [61,62], NTHi or M. catarrhalis [13]. A study from the Netherlands [59] and one from Israel [60] reported an inverse relationship in colonization patterns between serotypes of S. pneumoniae, including vaccine serotypes, and $S$. aureus in children. This may negate the desired effect of pneumococcal vaccination by increasing Staphylococcus diseases and possibly promoting an increase of multidrug-resistant $S$. aureus infections. The potential also exists for a more invasive and virulent organism such as $S$. pyogenes (group A $\beta$-hemolytic Streptococcus), which currently ranks as the fourthmost predominant pathogen, causing approximately $2-5 \%$ of pediatric AOM, to cause the more serious sequaelae of OM, mastoiditis [61,62]. The full ramifications of any unintended consequences of immunization with conjugated vaccines are yet to be elucidated and ongoing surveillance of isolates from the nasopharynx is critical.

\section{Models of vaccine efficacy}

$\mathrm{OM}$ is a disease of humans, and as such, there are limitations in the currently available animal models of human infection and their ability to address such factors as the pathogenesis of infection and the immune response to infection. A review of animal models used to study OM has reported that rabbits, gerbils, monkeys, ferrets, guinea-pigs, mice, chinchillas and rats have all been used successfully, with the rat and chinchilla model systems being used most extensively [63]. The animal model used by investigators largely depends on the nature of the scientific investigation. The rat model has been primarily used to study immunological 
responses in the middle ear to infection, screening of potential protein antigens for immunization and the assessment of mucosal immunization, focusing on the immunological response in the clearance of pathogens from the middle ear. Infection is established by direct inoculation into the middle ear. Although the chinchilla model is thought to more closely replicate human disease, the lack of the widespread availability of the animals and molecular reagents has limited studies. However, despite these limitations, the model has provided useful knowledge with respect to the pathogenesis of the disease, immune mechanisms in the middle ear and the evaluation of new vaccine antigens. The chinchilla is an excellent model of NTHi OM due to its sustainability in the nasopharynx and middle ear but is less acceptable for similar studies with S. pneumoniae and $M$. catarrhalis. The use of the mouse model is increasing in popularity with the increasing availability of knockout and transgenic mice and readily available reagents. More importantly, the mouse is widely used as an animal model for human diseases. Although animal models have provided useful data in assessing vaccine antigens, ultimately, it will be necessary to test a potential vaccine in humans to draw meaningful conclusions regarding the likely efficacy of a vaccine under development.

In addition to animal models, it has been recommended that human nasopharyngeal colonization should be assessed in efficacy studies [64]. Previous studies with conjugate vaccines for $H$. influenzae type $\mathrm{b}$ and pneumococcus have demonstrated $\mathrm{a}$ reduction in nasopharyngeal colonization $[49,65]$. It would not be unreasonable to suggest that vaccines for OM may confer protection by this mechanism in part. Regardless of its predictive value, the human nasopharyngeal colonization model may offer some insight into human mucosal immune responses and the effect of candidate vaccine antigens on nasopharyngeal colonization. In this context, in late 2005, a clinical trial was opened to examine the effect of pneumococcal vaccination on nasopharyngeal colonization in infants with $\mathrm{AOM}$ [201].

\section{Viral vaccines}

\section{Influenza vaccines}

The influenza vaccines licensed for use in young children ( $>6$ months of age) are a preparation of inactivated split or subunit virus vaccines. These vaccines are administered intramuscularly. Different study designs and risk cohorts and a lack of standardized criteria for diagnosis have offered conflicting evidence regarding the effectiveness of the influenza vaccine in preventing OM. Three comparable studies have shown a 30-36\% reduction in OM after influenza vaccination [66-68], whilst a fourth study that was limited by a lack of influenza epidemic during the second season showed no difference compared with placebo groups [69]. A systematic review assessing the effects of live attenuated and inactivated influenza vaccines against $\mathrm{AOM}$ in healthy children up to 16 years of age suggested no difference with placebo or standard care, but lacked statistical power [70]. In June 2003, a cold-adapted, trivalent, intranasal influenza vaccine (FluMist ${ }^{\mathrm{TM}}$, MedImmune Vaccines Inc.) was approved in the USA. The vaccine relies on the use of an attenuated strain that multiplies exclusively in the nose. Results of clinical trials in children and adults have demonstrated that the vaccine reduces the incidence of influenza and it is associated with a 30\% decrease in febrile OM in children [71]. As a live intranasal vaccine, it is anticipated that it would offer superior mucosal immunity compared with the currently available vaccines that are less immunogenic in very young children. Its principal advantage, in comparison with other influenza vaccines, is that it is administered nasally, which has greater acceptance and ease of administration than the intramuscular route. Studies in healthy children 12 months to 17 years of age showed FluMist $^{\mathrm{TM}}$ to be safe in children over 3 years of age with an observation that younger children have an increased risk of reactive airway disease [72]. Therefore, for safety reasons, it is licensed for use in people 5-49 years of age, and as such, is not currently available for use against AOM during the peak age of disease burden. An intranasal inactivated virosomal influenza vaccine has demonstrated a $44 \%$ reduction in new AOM episodes in children under 5 years of age with recurrent $\mathrm{AOM}$ and may prove to be a viable alternative [73]. It is unlikely that influenza will be included in a polymicrobial otitis vaccine considering the unpredictability of determining the influenza strain that will be dominant in any given year. It is generally accepted that an additional benefit of the influenza vaccine and any new formulations will be the capacity of the vaccine to reduce the incidence of $\mathrm{OM}$ as a secondary benefit.

\section{RSV vaccines}

The National Institute of Allergy and Infectious Diseases (NIAID), in its initiative to accelerate the development of vaccines to vaccine-preventable disease, identified a vaccine to RSV infection as a high priority [202]. Despite substantial efforts over the last 10 years towards producing a vaccine for RSV infection in children, a vaccine is not currently available. Several problems inherent in RSV vaccine development have dampened the enthusiasm of industry in progressing a strategy for RSV:

- The potential of infants failing to achieve protective immunity following vaccination owing to immunologic immaturity and/or suppression of the immune response by maternally derived antibody

- A successful vaccine would need to protect against subgroup $A$ and B strains of RSV and finally

- The legacy of failed RSV vaccines in the 1960s, one of which actually produced severe lower respiratory tract symptoms (bronchoconstriction and pneumonia) in infants [74]. Two immunized infants died as toddlers as a consequence of subsequent RSV infection. The cause of the deaths was attributed to bronchopneumoniae.

A comprehensive review on treatments for RSV disease has reported that RSV protein vaccine candidates, recombinant RSV subunit vaccine candidates, protein vaccine candidates for maternal immunization and live attenuated vaccine candidates have all been evaluated in humans [75]. Three types of RSV subunit vaccines have been evaluated in clinical trials: purified 
F glycoprotein vaccines (PFP-1, -2 and -3 ); BBG2Na, a peptide from the $G$ glycoprotein conjugated to the albumin-binding domain of streptococcal protein G; and copurified F, G and matrix $(\mathrm{M})$ proteins [75]. Of this group, the purified fusion proteins PFP-1, -2 and -3 have been shown to be safe and immunogenic in children over 12 months of age [76-78]. PFP-2 was well tolerated and immunogenic in women in their third trimester of pregnancy, with all 35 infants being born healthy and having higher vaccine-specific anti-F IgG binding antibody to RSV at birth, 2 and 6 months of life compared with infants of nonvaccinees [79]. Anti-F IgA and IgG concentrations in breast milk were elevated in mothers who received the vaccines.

MEDI-524TM (Numax) is a novel recombinant humanized IgG1 monoclonal antibody (mAb), currently being developed to potentially prevent serious lower respiratory disease caused by RSV in pediatric patients at high-risk of RSV disease. MEDI-524 (a derivative of palivizumab, the current standard of care for RSV disease) has exhibited enhanced neutralizing activity compared with palivizumab in an animal model [80]. An ongoing worldwide, Phase III trial assessing the efficacy of MEDI-524 in reducing RSV disease in high-risk infants ( $\leq 6$ months of age) commenced in late 2004 [203]. The comparative trial is designed to assess MEDI-524 against lower respiratory tract illness and OM. A follow-up trial is anticipated to start in mid-2006 [204]. MEDI-524 will be available in an inhaled formulation.

Live-attenuated vaccine candidates have been tested in infants [81,82]. Recently, a recombinant RSV vaccine with multiple mutations ( $\mathrm{rA2cp} 248 / 404 / 1030 \delta \mathrm{SH}$ ) has been shown, in a Phase I study, to be appropriately attenuated for young infants and has the potential to induce protective immunity in this population group [83]. Furthermore, it was observed that antibody might not be a significant mediator of protection induced by this live vaccine. Further work is planned to determine whether the recombinant vaccine can induce protective immunity against wild-type RSV. The same group of investigators have also been involved in a test-of-concept trial evaluating a combination RSV and PIV3 live, attenuated, intranasal vaccine for safety, viral replication and immunogenicity in children 6-18 months of age [84]. The results showed that the bivalent RSV/PIV3 vaccine was safe and immunogenic, and warrants further development. There have been no studies reporting the impact of these formulations on OM in infants and young children. Further insight into vaccine efficacy, RSV pathogenesis and the host's immune response to infection may become possible with the establishment of the chinchilla and mouse animal models of RSV infection of the nasopharynx and eustachian tube [85].

\section{PIV vaccines}

The human PIVs consist of four serotypes: PIV3 ranks second only to RSV as the leading cause of bronchiolitis and pneumoniae in infants under 6 months old; PIV1 and 2 cause illness after 6 months of age whereas PIV4 has been associated with mild upper respiratory tract illness in children and adults [202].
Although development of a vaccine to prevent PIV infections has been a high priority at the NIAID, a licensed vaccine is not yet available, with prospective manufacturers daunted with the prospect of developing a multivalent vaccine. To date, live-attenuated PIV3 vaccines that have been investigated in humans have been shown to be satisfactorily attenuated, immunogenic, and phenotypically stable in infants and young children [86,87]. The impact of PIV3-cp 45 on OM is doubtful, with 3 out of 32 seronegative vaccine recipients developing OM in Phase I studies [86], and no demonstrated difference in the occurrence of $\mathrm{AOM}$ or serous OM in 6-18-month-old healthy children in Phase II studies [87].

\section{Bacterial vaccines Pneumococcal vaccines} Composition

In 1983, the 23-valent pneumococcal polysaccharide vaccine, 23PPV (Pneumovax 23 $3^{\mathrm{TM}}$ [Aventis Pasteur, Lyon, France]), (serotypes 1, 2, 3, 4, 5, 6B, 7F, 8, 9N, 9V, 10A, 11A, 12F, 14, 15B, 17F, 18C, 19A, 19F, 20, 22F, 23F and 33F) was licensed in the USA. The pneumococcal serotypes included in the vaccine were chosen on the basis of the relative distribution of the individual serotypes that cause approximately $90 \%$ of invasive pneumococcal infections [88].

With the advent of the $H$. influenzae type $\mathrm{b}$ vaccine against meningitis in the 1980s came the technology to conjugate the pneumococcal polysaccharides to protein carriers. In 2000, a four-dose regimen of a 7-valent pneumococcal conjugate vaccine (PCV7) (Prevenar ${ }^{\mathrm{TM}} /$ Prevnar $^{\mathrm{TM}}$, Wyeth-Lederle Vaccines) (serotypes $4,6 \mathrm{~B}, 9 \mathrm{~V}, 14,18 \mathrm{C}, 19 \mathrm{~F}$ and $23 \mathrm{~F}$ ), conjugated to a non-toxic diphtheria-toxin variant (CRM197), was licensed for use in infants and toddlers in the USA. Since then, marketing approval has been granted in the European Union, Australia and several other countries. Those serotypes included in the vaccine are estimated to cause $80 \%$ of invasive pneumococcal disease in children and approximately $60 \%$ of pneumococcal AOM [89,90]. PCV7 has the potential coverage of over $85 \%$ of the pneumococcal isolates for the USA, $60-70 \%$ for Europe, approximately 55\% for Asia [91] and around 48\% in Scotland [92]. However, serotype prevalence may vary not only with geographical location but also with time.

Other PCVs are currently under development that differ with regard to the nature of the carrier protein and the number of included serotypes. These new formulations attempt to reduce the influence of any increase in the load of a carrier might have on the immunogenicity of other concomitantly injected conjugate vaccines that use the same protein carrier and the PCV itself, and to increase the serotype coverage of pneumococcal vaccines. These new vaccines include nine serotypes (contains those serotypes of the 7-valent vaccine with two additional serotypes, 1 and 5) or 11 serotypes (contains those serotypes of the 9-valent vaccine with two additional serotypes, 3 and 7F), which are conjugated to one of several carrier proteins, including CRM197, tetanus protein, diptheria toxoid, Neisseria meningitidis group B outer-membrane protein complex (OMPC) and H. influenzae protein D. 


\section{Immune response to pneumococcal vaccination}

Functional immunity to pneumococcus is thought to be a result of opsonizing antibody. Young children less than 2 years of age are unable to respond effectively to polysaccharide antigens due to immaturity of the immune system that is unable to make effective T-cell independent responses. This renders the polysaccharide vaccine virtually useless against pneumococcal $\mathrm{OM}$ and invasive disease in children of this age when they are most prone to OM. 23PPV has been used as a booster after primary immunization with a PCV in order to reduce immunization costs (23PPV being less expensive than pneumococcal conjugated vaccine) and to induce higher serum [52,93] and salivary antipneumococcal antibodies, in higher concentrations [94] than a conjugate booster.

Unlike the polysaccharide vaccines, the PCVs are able to elicit a T-cell-dependent antibody response to the protein carrier and polysaccharides, making them highly efficacious against invasive disease in children younger than 2 years of age. They are able to induce a primary immune response in young children after one or more doses. PCVs have been demonstrated to induce both humoral and mucosal responses. The IgG serum antibodies are functionally active, as demonstrated by their high avidity and opsonophagocytic activity, and consist of subclass IgG1 [95,96], but after booster immunization usually consist of both IgG1 and IgG2 [95]. Several studies have reported both IgA and IgG mucosal responses as measured by antibody in saliva [93,97-99]. The antibody response is predominantly of subclass IgA1 [94], and the antibodies persist for only a short period [97,100]. There is a positive correlation between serum and salivary IgG levels suggesting that salivary IgG has diffused from serum [98]. Furthermore, serum serotype-specific pneumococcal anticapsular IgG responses have been reported to be correlated inversely with nasopharyngeal acquisition of pneumococcus [101]. Consistent with this observation, several studies have shown a significant reduction in nasopharyngeal carriage in vaccine-serotype pneumococci in infants as a result of pneumococcal conjugate vaccination [51,53,55,102,103]. As the burden of nasopharyngeal colonization is a major risk factor of AOM $[44,45]$, it might be predicted that an immune response that reduces nasopharyngeal colonization would be efficacious against AOM. However, in some studies where there were apparent drops in vaccine carriage, there were compensatory rises in nonvaccine serotypes or other bacterial pathogens [51-53,55,56]. Modification of the microbial ecology of the nasopharynx by vaccination could at least partly explain the different efficacy observed for AOM compared with invasive disease [104] following vaccination.

\section{Efficacy of pneumococcal vaccination}

In clinical trials to date, PCVs have been shown only to be modestly beneficial against OM. Both Finnish and Californian trials have reported a 6\% OM efficacy point estimate [105,106]. In the Californian study, PCV7 demonstrated a decrease in AOM visits by $8.9 \%$, AOM episodes by $7 \%$ and recurrent episodes by $9.3 \%$ [106]. In the two Finnish trials,
PCV7 [56] and a 7-valent PCV conjugated to an outer membrane protein complex (OMPC) of $N$. meningititis (PncOMPC) [52] showed a similar reduction of 56 and $57 \%$, respectively, in $\mathrm{AOM}$ due to vaccine-type pneumococci. PCV7 reduced the frequency of episodes due to serotypes that cross-react with those in the vaccine by $51 \%$ [56. The overall reduction of AOM irrespective of aetiology was $6 \%$ for PCV7; however, there was an increase of $33 \%$ in the cases of pneumococcal AOM caused by nonvaccine serotypes [56]. Of significance was a $24 \%$ reduction in tympanostomy tube procedures [105], suggesting a reduction of severity of disease might have occurred.

It is well documented that onset of OM during the first 6 months of life is one of the strongest risk determinants for recurrent OM and chronic OME [45]. An ongoing Phase II study is investigating neonatal PCV7 immunization of highrisk infants in Papua New Guinea [205]. It is hypothesized that a three-dose regimen over 3 months in newborns may stimulate antibody to protect against invasive disease and reduce the burden of early carriage.

Two Dutch studies with PCV7 followed by a booster of 23PPV in children 1-7 years of age failed to show any protection of vaccination against recurrent AOM [53,107]. Overall nasopharyngeal carriage of pneumococci was not affected by vaccination because of concurrent increase in nonvaccine serotypes [53]. Therefore, the data does not lend support to the use of PCV7 in the management of recurrent AOM in previously unvaccinated toddlers and children. Furthermore, a recent study showed that combined PCV7 and 23PPV does not prevent recurrence of OME among children 2-8 years of age with a history of persistent OME [108]. It may be that the PCV protects against $\mathrm{AOM}$ and the progression to an otitis-prone condition, when given in early infancy however, once the recurrence is established, is no longer beneficial.

A 9-valent pneumococcal vaccine conjugated to CRM197 (PNCRM9) has been shown to decrease OM by $17 \%$ in children 1-3 years of age [109]. An 11-valent mixed carrier vaccine, PncDT11 (polysaccharide antigens of serotypes 1, 4, 5, $7 \mathrm{~F}, 9 \mathrm{~V}, 19 \mathrm{~F}$ and $23 \mathrm{~F}$ conjugated to tetanus protein, and serotypes $3,6 \mathrm{~B}, 14$ and $18 \mathrm{C}$ conjugated to diphtheria toxoid) has been reported to be safe and immunogenic in infants from 2 months of age [110,111]. Its impact on OM was not addressed. Immunogenicity studies are also currently being conducted against a 13-valent PCV in healthy infants [206].

A 11-valent pneumococcal vaccine conjugated to H. influenzae-derived protein D (Pn-PD) has been shown to be safe in infants and induces antibody responses to all components of the vaccine, including protein D [112]. More recently, Phase III studies have demonstrated Pn-PD to confer protection against $\mathrm{AOM}$ caused by vaccine pneumococcal serotypes (52.6\%), as well as AOM caused by NTHi (35.3\%) and any pneumococci (51.5\%) [113].

The reasons for the disappointing impact of pneumococcal vaccines on AOM despite good antibody responses may be multifactorial: 
- Serotype replacement following vaccination may result in middle-ear disease caused by pneumococci of nonvaccine serotypes.

- Pneumococcal vaccination may also induce replacement by other pathogens involved in middle-ear disease such as NTHi or $M$. catarrhalis.

- Suboptimal IgG responses to some serotypes. Animal [114] and human [52,56] studies have shown that protection from disease is dependent upon serotype-specific humoral pneumococcal anticapsular IgG concentrations. Analysis of combined results from the two Finnish studies [115] showed a clear correlation between IgG concentrations 4 weeks after vaccination and protection against $\mathrm{AOM}$ caused by serotypes $6 \mathrm{~B}$, $19 \mathrm{~F}$ and $23 \mathrm{~F}$. The serotype efficacy ranged from $25 \%$ for $19 \mathrm{~F}$ to $84 \%$ for $6 \mathrm{~B}$.

The results of the studies of pneumococcal conjugate vaccination in children raise important questions regarding the nature of the immune response in the middle ear. Why does a vaccine with excellent outcomes against an invasive disease perform so poorly against infection with the same microbes in the ear? There is now a body of evidence to suggest that the middle ear is, at least in part, dependent on mucosal immunity and that a mucosal immunization approach may be more efficacious than immunization by a systemic route. In this context, further studies are needed to better characterize immune mechanisms in the middle ear. Additional studies will be required to determine the most efficacious route of immunization and choice of adjuvant. A mucosal strategy should not be discounted.

\section{Maternal immunization against pneumococcal disease}

A Cochrane review has assessed the effect of pneumococcal vaccination during pregnancy for preventing pneumococcal disease during the infant's first months of life [116]. The review found there was not enough information to conclude whether vaccination with the $23 \mathrm{PPV}$ during pregnancy led to fewer infant infections. However, it has been shown in the chinchilla OM model that maternal heptavalent pneumococcal polysaccharide-protein vaccine immunization reduces the burden of early infant $\mathrm{OM}$ and invasive pneumococcal disease [117].

\section{Immunization against NTHi AOM}

The only study conducted to date that has shown vaccineinduced protecion against NTHi AOM is the 11-valent pneumococcal vaccine conjugate to the $H$. influenzae-derived protein D [113]. Although 35.3\% efficacy was observed with this vaccine against $\mathrm{AOM}$ caused by $\mathrm{NTHi}$, there was no correlation between efficacy and anti-protein D antibodies. Further studies are required to determine the nature of NTHi immunity stimulated by protein D. Other conserved NTHi proteins that stimulate cellular immunity or antibodies that block attachment may need to be added to the vaccine composition to improve efficacy against AOM caused by NTHi. Furthermore, it will also be important in future trials to control for the possible interaction between the reduction in pneumococcal
AOM and NTHi infections. It may be necessary to include a trial arm where only the carrier protein-D and additional NTHi antigens are tested to determine the true effect of these antigens on NTHi AOM.

\section{Pneumococcal protein antigens}

In parallel to the development of conjugate vaccines, other pneumococcal antigens common to all serotypes are also being tested. The virulence proteins, pneumococcal surface-adhesin A (PsaA), pneumococcal surface-protein A (PspA) and neuraminidase, yield encouraging results in animal models. PspA elicits protection against OM in a rat model [118]. PspA is serologically variable, however, a recombinant form of the protein has been shown to be immunogenic in humans [119]. The immunity to PspA is sufficiently crossreactive for it to be considered as a vaccine candidate. PspA and recombinant lipidated PsaA reduced pneumococcal carriage in mice [120]. Issues regarding antigen heterogeneity and toxicity associated with some virulence factors such as pneumolysin have hampered further development of a vaccine incorporating these antigens. However, a combination vaccine of PspA, PsaA and PdB (a mutant form of pneumolysin) has been shown to produce a synergistic protective response in mice [121]. As these proteins appear to function at different stages of the pathogenic process, it is anticipated that a combined pneumococcal vaccine may provide protection against a wider variety of strains over immunization with any one of the protein antigens. Neuraminidase affords protection against S. pneumoniae nasopharyngeal colonization and OM in chinchillas [122].

An innovative, subunit vaccine, PGCvax ${ }^{\mathrm{TM}}$, is based on two novel pneumococcal surface proteins (BVH-3 and -11). Studies in a mouse model demonstrated that the proteins are highly conserved throughout the pneumococcal species and are able to elicit protective antibodies [123]. Phase I clinical studies have shown the recombinant vaccines to be well tollerated and immunogenic in adults [202]. It is planned to extend the Phase I study to include infants.

The potential advantages of a pneumococcal protein vaccine over a polysaccharide-protein conjugate vaccine include:

- The use of formulations that have a combination of proteins likely to target more than one mechanism of pneumococcal carriage and colonization

- Less expense, abrogating the cost of conjugation and product purification

\section{NTHi vaccine candidates}

The development of a vaccine to NTHi has been given the highest priority by the NIAID. However, progress has been hindered by the lack of clinical studies identifying an in vitro correlate of immunity to NTHi infection. Recommendations for the characterization of the protective immune responses to NTHi include bactericidal antibody and/or inhibition of adherence to relevant host cells, and protective responses in at least two animal models [64]. Preclinical studies have identified various antigens as vaccine candidates. 
Lipooligosaccharide (LOS) is a major surface antigen and virulence factor of NTHi, capable of eliciting bactericidal and opsonic antibodies in animals $[124,125]$. A potential vaccine candidate, 9274LOS, is structurally heterogeneous [126] and shares common epitopes among NTHi LOSs [124]. When prepared as a detoxified protein conjugate (i.e., dLOS linked to tetanus toxoid $[\mathrm{TT}]$ or high molecular weight $[\mathrm{HMW}]$ protein from NTHi) it was shown to have high immunogenicity in mice and rabbits and induced complement-mediated bactericidal activity against NTHi in rabbits [127]. Furthermore, it was able to elicit immunity against NTHi OM in a chinchilla model [128] and significantly enhance NTHi clearance in the mouse nasopharynx [129]. A Phase I clinical trial has demonstrated that it is well tolerated in adults [130].

P6 is highly conserved among all H. influenzae strains. Immunization with $\mathrm{P} 6$ induces protection in the pulmonary clearance model in the rat [131], mouse [132] and chinchilla models of OM [133]. It is a target of human bactericidal antibody, which is associated with protection from OM [133]. Intranasal immunization with native P6 [134] and recombinant P6 protein coupled to adamantlyamide dipeptide (AdDp) as mucosal adjuvant confers antigen-specific protection against OM by NTHi in a mouse model [135], whilst P6 coupled to cholera toxin induced P6-specific sinus mucosal and systemic immunological responses mainly of the IgA and IgG isotypes in rats [136]. A recent study has shown that maternal intranasal immunization with P6 induced specific immune responses in sera and colostrums of mother mice and protective antibodies were transferred from mother to neonate mice through transplacental transfer during pregnancy and through breast milk after birth [137]. Furthermore, intranasal immunization with P6 has been shown to modulate cellular responses with an increase in memory $\mathrm{T}$ cells in middleear mucosa [138] and decreased concentrations of tumour-necrosis factor- $\alpha$ in middle-ear effusions [134]. Recent data has shown that P6 of NTHi contains a single immunodominant T-cell epitope and that both B- and T-cell responses are important in the ability of P6 to induce protection in the murine model [132]. It would follow that a clinical study to determine if $\mathrm{T}$ cells from humans would also recognize the T-cell epitope should be conducted.

OMP26 is highly conserved and is associated with protection against NTHi strains following parenteral and mucosal immunization in the chinchilla and rat models, respectively $[139,140]$. Furthermore, these studies demonstrated that OMP26 induced a high-titer and specific response in both animal models. OMP26 is a strong vaccine candidate, as demonstrated by its efficacy as an immunogen against OM caused by NTHi in two diverse rodent models.

OMP P5 fimbrin adhesin-derived peptides (LB1 and LPDLB1(f) $)_{2,1,3}$ ) protect against both homologous and heterologous strains in the chinchilla nasopharyngeal clearance model and the $\mathrm{OM}$ model in the rat by inducing a specific antibody response [139,141]. As described above for OMP26, the demonstrated efficacy of P5-derived vaccine candidates in two animal models provides strong support for further evaluation for their inclusion in a vaccine directed against NTHi-induced OM.
Lipoprotein $\mathrm{D}$ is highly conserved in $H$. influenzae strains. Lipoprotein $\mathrm{D}$ is used predominantly as a carrier protein for NTHi [139,141], whilst protein D (a recombinant deacylated form of LPD) has been used more recently as a carrier protein for pneumococcal antigens $[112,113]$. In this formulation, significant protection (35.3\%) was observed against $\mathrm{AOM}$ caused by NTHi [113].

The OMP P2 constitutes nearly 50\% of the total OMP of NTHi; however, it has not previously been considered as a strong vaccine candidate because antibodies directed against it have been shown to be highly strain-specific [202]. Further studies into the conserved regions of the $\mathrm{P} 2$ porin protein showed that antibodies to loop 6 have bactericidal activity against multiple strains of NTHi supporting the concept of using conserved regions of the $\mathrm{P} 2$ protein as vaccine antigens [142].

$\mathrm{HtrA} / \mathrm{H} 91 \mathrm{~A}$ (Hin47) is the nonproteolytic recombinant form of the $H$. influenzae HtrA stress-shock protein. The vaccine relies on an adhesin-receptor technology and is combined with an adjuvant. It has been shown to be partially protective in the chinchilla model of NTHi-induced OM [143]. Although Phase I testing in adults have shown Hin 47 to be safe and immunogenic, it is yet to be assessed in the pediatric population [202].

HMW1 and HMW2 are a family of HMW-adhesins that are encoded by genes that are $80 \%$ identical and found in approximately $75 \%$ of NTHi strains [202]. The HMW proteins are targets of human opsonizing antibodies that demonstrate protection against NTHi in the chinchilla OM model [144]. The HMW-adhesin, Hap, when conjugated to mutant cholera toxin, reduced nasopharyngeal colonization when mice were challenged intranasally with a heterologous strain of NTHi [145]. A recombinant form of the cell-binding domain of the Hap protein was capable of eliciting crossreacting antibodies and also reduced nasopharyngeal colonization suggesting that it may be worthy of further investigation as a vaccine candidate [146].

The NTHi P4 lipoprotein is highly conserved and elicits antibodies that are broadly cross-reactive and have bactericidal activity $[147,148]$. A recombinant form of $\mathrm{P} 4$ has been shown to reduce nasopharyngeal colonization in a mouse model after intranasal immunization [149]. However, as a highly specific acid phosphomonoesterase, its inclusion in a vaccine for infants is challenging, therefore, a nonenzymatically active recombinant $\mathrm{P} 4$ protein has been developed and shown to generate bactericidal antibodies [150].

\section{Moraxella catarrhalis vaccine candidates}

To date, the major focus of investigation in identifying M. catarrhalis vaccine antigens has been on OMPs and LOSs. Significantly, UspA, CD, and CopB elicit bactericidal antibodies [151-153]. Immunization with UspA [151], recombinant CD [154], or CopB [153] enhanced pulmonary clearance of M. catarrhalis in a mouse model. M. catarrhalis serotype A dLOS and serotype B dLOS conjugated to protein carriers elicited strong bactericidal antibodies in animal models $[155,156]$ 
and conferred protection in a pulmonary infection model [157]. There have been no human studies investigating the prospect of immunizing against $\mathrm{OM}$ caused by $M$. catarrhalis.

\section{Expert commentary}

$\mathrm{OM}$ is a multifactorial disease that primarily affects three-quarters of the developed world's children under 3 years of age. Although associated mortality is low, the burden of the disease on humanity is enormous. The predominant cause of OM is infection of the middle-ear with microbes that are mainly commensals of the nasopharynx. The anatomical orientation of the eustachian tube in association with a number of risk factors predisposes infants and young children to middle-ear infection. Although there has been a significant body of research undertaken towards the development of a suitable vaccine against the disease, the polymicrobial nature of the infection presents major obstacles, particularly with respect to formulation, trialling and manufacture of a vaccine. At present, the price of complex and multivalent conjugates, such as the PCV, are high, with a fourdose regimen of the PCV7 costing in excess of US\$200 [158]. The limitation to development of this technology is likely to be commercial. It has proven to be very expensive to develop a pneumococcus vaccine. The involvement of the pharmaceutical industry in the development of new respiratory vaccines has been stalled due to the consolidation within the pharmaceutical industry, adverse experiences with live-attenuated viral vaccines (e.g., rotavirus and RSV), and the formidable costs in vaccine development, clinical trials and manufacturing facilities. Complicating the matter further is a US FDA requirement that before a new PCV may be licensed, it must be demonstrated to be 'noninferior' to existing vaccines $[159,160]$. With the next generation of PCVs to enter the market, it may not be feasible to conduct additional efficacy trials comparing a candidate PCV to PCV7 for licensure. An alternative and more cost-effective method for comparing vaccines would be to conduct clinical trials based on comparing immunological responses where parameters that best correlate with protection have been quantified. To this end, it will be necessary to develop functional assays to measure correlates of OM protection to the various pathogens presently under investigation, for instance, NTHi, S. pneumoniae, M. catarrhalis, influenza virus, RSV and PIV.

There is a general consensus that the successful vaccine for OM will most likely include more than one antigen. A strategy in the first instance would be the development of a formulation containing antigens of the two major bacterial agents, NTHi and S. pneumoniae. This approach has been exemplified by the recent use of an NTHi protein as a carrier for pneumococcal polysaccharides that was shown to be partially effective in reducing the incidence of OM caused by NTHi and S. pneumoniae. For NTHi, OMP26 and the OMP P5 fimbrin adhesin-derived peptides could be considered as lead vaccine candidates. Although the choice is somewhat more complex for $S$. pneumoniae, PspA could be considered the leading vaccine candidate for this bacterium, at this point in time. Efficacy may be improved by the addition of PsaA and PdB to the formulation, as well as ensuring an appropriate representation of proteins from PspA family 1 and 2 . These antigens are well characterized, immunogenic and efficacious in animal models and are now available for human studies. It is feasible that this approach could see the development of a highly efficacious vaccine available within the next 5 years given an appropriate investment by the vaccine industry. It might be predicted that additional NTHi antigens and replacement of pneumococcal polysaccharides conjugated to a protein carrier with pneumococcal protein antigens will increase efficacy. The next strategy would be to add to this core formulation additional antigens as they become available, particularly for M. catarrhalis and RSV. To date, there has been the development of a live-attenuated RSV vaccine that is well tolerated in infants and demonstrates protection by challenge studies [83]. Clinical testing of the vaccine candidates was conducted by a consortium of investigators as part of an agreement between industry (Wyeth Vaccines Research) and government laboratories (NIAID and National Institutes of Health). A combination vaccine of RSV and PIV3 may have some impact on the incidence of OM [84].

Although the rapid development of this approach will present a serious challenge for the current paradigm concerning clinical trials that exist within the regulatory authorities worldwide, it is feasible that an efficacious vaccine against the major causative microbes for OM could be achieved within the next decade. This will only be achieved with the fostering of cooperative agreements between industry, government laboratories and academics to progress the evaluation of the significant number of promising vaccine candidates in human trials. It is most likely that the formulations will not induce sterile immunity against $\mathrm{OM}$ pathogens. Indeed, this may not be desirable given that they are part of the commensal flora of the nasopharynx and sterile immunity may result in replacement flora with greater pathogenic potential. The aim should be to reduce nasopharyngeal load and induce appropriate immune responses when microbes ascend the eustachian tube.

There is substantial evidence that indicates that $\mathrm{OM}$ often goes unrecognized in the community and as a result the incidence and subsequent sequelae such as hearing loss may be higher than that reported. The failure to develop programs to screen routinely for $\mathrm{OM}$ and research improved treatment strategies is a global public health disgrace.

\section{Five-year view}

Over the next 5 years, it could be expected that a highly efficacious multivalent vaccine containing both NTHi and S. pneumoniae antigens will be produced commercially. Antigens for these microbes are currently available and needing clinical trial. By 2011, it is feasible that a vaccine containing additional antigens for M. catarrhalis and RSV could be available. However, this will require significant commitment from the vaccine industry and more flexible regulatory approaches to trialing these formulations. Regretably, tens of millions of children will continue to develop major hearing disabilities as a result of OM over the next 5 years. 


\section{Key issues}

- Otitis media (OM) is a major cause of morbidity in the world's children.

- $\mathrm{OM}$ is caused by microbial infection of the middle ear as a result of the anatomical orientation of the eustachian tube in association with a number of risk factors in infants and young children.

- The predominant microbes that cause infection are nontypeable Haemophilus influenzae (NTHi), Streptococcus pneumoniae, Moraxella catarrhalis, respiratory syncytial virus (RSV), rhinovirus, parainfluenza (PIV) and influenza.

- The potential exists for the rapid commercial development of a polyvalent vaccine for NTHi and S. pneumoniae.

- Candidate vaccine antigens have been identified in animal models for NTHi and S. pneumoniae.

- Promising research is being undertaken towards the identification of vaccine antigens for M. catarrhalis, RSV and PIV.

- Some clinical trials for RSV and PIV have been conducted, but efficacy for OM have not been determined.

- There needs to be a commitment from the vaccine industry, research institutions and regulatory authorities to work in partnership to rapidly trial new vaccine formulations specifically developed for $0 \mathrm{M}$.

- Further research is necessary to characterize the nature of the immune response in the ear and particularly what differentiates it from the respiratory tract. Mucosal immunity needs to be explored further.

- Significant investment in public health initiatives is required to provide for early diagnosis of OM and interventions.

- The vaccine has to be affordable and accessible to the children of the world and in sustained supply.

- Pathogen replacement following vaccination is a major concern and ongoing surveillance studies will be required following the introduction of a polymicrobial vaccine for OM.

- Vaccination offers the greatest potential to deliver a sustained reduction in the burden of OM in children globally.

\section{References}

Papers of special note have been highlighted as:

- of interest

-• of considerable interest

1 Teele DW, Klein JO, Rosner B. Epidemiology of otitis media during the first seven years of life in children in Greater Boston: a prospective, cohort study. J. Infect. Dis. 160, 83-94 (1989).

2 Teele DW, Klein JO, Chase C, Menyuk P, Rosner BA; and the Greater Boston Otitis Media Study Group. Otitis media in infancy and intellectual ability, school achievement, speech, and language at age 7 years. J. Infect. Dis. 162, 685-694 (1990).

3 Bennett KE, Haggard MP, Silva PA, Stewart IA. Behaviour and developmental effects of otitis media with effusion into the teens. Arch. Dis. Child. 85, 91-95 (2001).

4 Rovers MM, Schilder AG, Zielhuis GA, Rosenfeld RM. Otitis media. Lancet 465-473 (2004).

- A comprehensive review on the epidemiology, pathogenesis and management of otitis media $(\mathrm{OM})$.

5 Advisory Committee on Immunization Practices. Preventing pneumococcal disease among infants and children: Recommendations of the Advisory Committee on Immunization Practices (ACIP). MMWR Recomm. Rep. 49, 1-35 (2000).
6 Finkelstein JA, Metlay JP, Davis RL et al. Antimicrobial use in defined populations of infants and young children. Arch. Pediatr. Adolesc. Med. 154, 395-400 (2000).

7 Brixner DI. Improving acute otitis media outcomes through proper antibiotic use and adherence. Am. J. Manag. Care 11(Suppl.), S202-S210 (2005).

8 Joki-Erkkila VP, Laippala P, Pukander J. Increase in paediatric acute otitis media diagnosed by primary care in two Finnish municipalities - 1994-5 versus 1978-9. Epidemiol. Infect. 121, 529-534 (1998).

9 Fried VM, Makuc DM, Rooks RN. Ambulatory health care visits by children: principal diagnosis and place of visit. Vital Health Stat. 137, 1-23. (1998).

10 Charles J, Pan Y, Britt H. Trends in childhood illness and treatment in Australian general practice, 1971-2001. MJA 180, 216-219 (2004).

11 Gonzales R, Malone DC, Maselli JH, Sande MA. Excessive antibiotic use for acute respiratory infections in the United States. Clin. Infect. Dis. 33, 757-762 (2001).

12 Howard DH, McGowan JE Jr. Initial and follow-up costs by treatment outcome for children with respiratory infections. Pediatrics 113, 1352-1356 (2004).
13 Casey JR, Pichichero ME. Changes in frequency and pathogens causing acute otitis media in 1995-2003. Pediatr. Infect. Dis. J. 23, 824-828 (2004).

- Investigates the evolving shift in $\mathrm{OM}$ pathogens and the association with $\mathrm{OM}$ treatment failures since the widespread use of the pneumococcal conjugate vaccine.

14 Dowell SF, Butler JC, Giebink GC. et al. Acute otitis media: management and surveillance in an era of pneumococcal resistance a report from the Drug-resistant Streptococcus pneumoniae Therapeutic Working Group. Pediatr. Infect. Dis. J. 18, 1-9 (1999).

15 Hoover H, Roddey OF. The overlooked importance of tympanic membrane bulging. Pediatrics 115, 513 (2005).

16 Pellman H. Thoughts on the American Academy of Pediatrics/American Academy of Family Physicians Clinical Practice Guidelines on acute otitis media: a different perspective. Pediatrics 115, 1443-1444 (2005).

17 Pichichero ME, Casey JR. Acute otitis media: making sense of recent guidelines on antimicrobial treatment. J. Fam. Pract. 54, 313-322 (2005).

18 American Academy of Pediatrics Subcommittee on Management of Acute Otitis Media. Diagnosis and management of acute otitis media. Pediatrics 113, 1451-1465 (2004). 
19 American Academy of Pediatrics. Otitis media with effusion. Pediatrics 113 , 1412-1429 (2004).

20 Glasziou PP, Del Mar CB, Sanders SL, Hayem M. Antibiotics for acute otitis media in children (Cochrane review). In: The Cochrane Library, Issue 3, John Wiley and Sons, Ltd., Chichester, UK (2004).

21 Garcia-Rodriguez JA, Fresnadillo Martinez MJ. Dynamics of nasopharyngeal colonization by potential respiratory pathogens. J. Antimicrob. Chemother. 50(Suppl.), 59-73 (2002).

22 Casselbrant M, Mandel EM. Epidemiology: In: Evidence-based otitis media. Rosenfeld RM, Bluestone CD, BC Decker (Eds.), Hamilton, ON, Canada 117-136 (1999).

23 Stool SE, Berg AO, Berman S et al. Otitis media with effusion in young children, Clinical Practice Guideline, Number 12. AHCPR Publication No. 94-0622. Agency for Health Care Policy and Research, Public Health Services US Department of Health and Human Services, Rockville, MD, USA (1998).

24 Williams RL, Chalmers TC, Stange KC, Chalmers FT, Bowlin SJ. Use of antibiotics in preventing recurrent acute otitis media and in treating otitis media with effusion. A meta-analytic attempt to resolve the brouhaha. JAMA 270, 1344-1351 (1993).

25 Daly K, Casselbrant M, Hoffman $\mathrm{H}$ et al. Epidemiology, natural history, and risk factors. Annal. Otol. Rhinol. Laryngol. 111, 19-25 (2002).

26 Faden H, Duffy L, Williams A, Krystofik D, Wolf J. Epidemiology of nasopharyngeal colonization with nontypeable Haemophilus influenzae in the first two years of life. J. Infect. Dis. 172, 132-135 (1995).

27 Paradise JL, Rockette HE, Colborn K et al. Otitis media in 2253 Pittsburgh-area infants: prevalence and risk factors during the first two years of life. Pediatrics 99, 318-333 (1997).

28 Heikkinen T, Chonmaitree T. Importance of respiratory viruses in acute otitis media. Clin. Microbiol. Rev. 16, 230-241 (2003).

29 Klein J. Otitis media. Clin. Infect. Dis. 19, 823-833 (1994).

30 Leach A, Boswell JB, Asche V et al. Bacterial colonization of the nasopharynx predicts very early onset and persistence of otitis media in Australian aboriginal infants. Pediatr. Infect. Dis. J. 13, 983-989 (1994).

31 Post JC, Preston RA, Aul JJ et al. Molecular analysis of bacterial pathogens in otitis media with effusion. JAMA 273, 1598-1604 (1995).
32 Hendolin P, Markkanen A, Ylikoski J et al. Use of multiplex PCR for simultaneous detection of four bacterial species in middle ear effusions. J. Clin. Micro. 35, 2854-2858 (1997).

33 Gok U, Bulut Y, Keles E et al. Bacteriological and PCR analysis of clinical material aspirated from otitis media with effusions. Int. J. Pediatr. Otorhinolaryngol. 60, 49-54 (2001).

34 Pitkaranta A, Virolainen A, Jero J et al. Detection of rhinovirus, respiratory syncytial virus, and corona virus infections in acute otitis media by reverse transcriptase polymerase chain reaction. Pediatrics 102, 291-295 (1998).

35 Sung BS, Chonmaitree T, Broemeling LD et al. Association of rhinovirus infection with poor bacteriologic outcome of bacterial-viral otitis media. Clin. Infect. Dis. 17, 38-42 (1993).

36 Chonmaitree T, Henrickson KJ. Detection of respiratory viruses in the middle ear fluids of children with acute otitis media by multiplex reverse transcription:polymerase chain reaction assay. Pediatr. Infect. Dis. J. 19, 258-260 (2000).

37 Ishibashi T, Monobe H, Nomura Y, Shinogami M, Yano J. Multiplex nested reverse transcription-polymerase chain reaction for respiratory viruses in acute otitis media. Ann. Otol. Rhinol. Laryngol. 112, 252-257 (2003).

38 Osterhaus A, Fouchier R. Human metapneumovirus in the community. Lancet 361, 890-891 (2003).

39 Arden KE, Nissen MD, Sloots TP, Mackay IM. New human coronavirus, HCoV-NL63, associated with severe lower respiratory tract disease in Australia. J. Med. Virol. 75, 455-462 (2005).

40 Williams JV, Wang CK, Yang CF, et al. The role of human metapneumovirus in upper respiratory tract infections in children: a $20-$ year experience. J. Infect. Dis. 193, 387-395 (2006).

- Using the highly sensitive PCR technique, the newly discovered human respiratory pathogen metapneumovirus is found with similar frequency in the nasopharynx as other middle-ear pathogens.

41 Kodama S, Hirano T, Suenaga S, Abe N, Suzuki M. Eustachian tube possesses immunological characteristics as a mucosal effector site and responds to P6 outer membrane protein of nontypeable Haemophilus influenzae. Vaccine 24, 1016-1027 (2006).

42 Suenaga S, Kodama S, Ueyama S, Suzuki M, Mogi G. Mucosal immunity of the middle ear: analysis at the single cell level. Laryngoscope 111(2), 290-296 (2001).
43 Clancy RL, Cripps AW, Yeung S et al. Salivary and serum antibody responses to Haemophilus influenzae infection in Papua New Guinea. PNG Med. J. 30, 271-276 (1987).

44 Faden H, Duffy L, Wasielewski R, Wolf J, Krystofik D, Tung Y. Relationship between nasopharyngeal colonization and the development of otitis media in children. Tonawanda/Williamsville Pediatrics. J. Infect. Dis. 175, 1440-1445 (1997).

45 Faden H, Waz MJ, Bernstein JM, Brodsky L, Stanievich J, Ogra PL. Nasopharyngeal flora in the first three years of life in normal and otitis-prone children. Ann. Otol. Rhinol. Laryngol. 100, 612-615 (1991).

46 Straetemans M, Wiertsema SP, Sanders EA et al. Immunological status in the aetiology of recurrent otitis media with effusion: serum immunoglobulin levels, functional mannose-binding lectin and $\mathrm{Fc}$ receptor polymorphisms for IgG. J. Clin. Immunol. 25, 78-86 (2005).

47 Kay DJ, Nelson M, Rosenfeld RM. Meta-analysis of tympanostomy tube sequelae. Otolaryngol. Head Neck Surg. 124, 374-380 (2001).

48 Huang SS, Platt R, Rifas-Shiman SL, Pelton SI, Goldmann D, Finkelstein JA. PostPCV7 changes in colonizing pneumococcal serotypes in 16 Massachusetts communities, 2001 and 2004. Pediatrics 116(3), E408-E413 (2005).

49 O’Brien KL, Dagan R. The potential indirect effect of conjugate pneumococcal vaccines. Vaccine 21, 1815-1825 (2003).

- A review of the pneumococcal vaccines and the potential effects they may have on nasopharyngeal pneumococcal carriage and antibiotic carriage and use.

50 Spratt BG, Greenwood BM. Prevention of pneumococcal disease by vaccination: does serotype replacement matter? Lancet 356, 1210-1211 (2000).

51 Ghaffar F, Barton T, Lozano J et al. Effect of the 7-valent pneumococcal conjugate vaccine on nasopharyngeal colonization by Streptococcus pneumoniae in the first 2 years of life. Clin. Infect. Dis. 39, 930-938 (2004).

52 Kilpi T, Ahman H, Jokinen J. et al. Protective efficacy of a second pneumococcal conjugate vaccine against pneumococcal acute otitis media in infants and children: randomized, controlled trial of a 7 valent pneumococcal polysaccharidemeningococcal outer membrane protein complex conjugate vaccine in 1666 children. Clin. Infect. Dis. 37, 1155-1164 (2003). 
53 Veenhoven R, Bogaert D, Uiterwaal C et al. Effect of conjugate pneumococcal vaccine followed by polysaccharide pneumococcal vaccine on recurrent acute otitis media: a randomised study. Lancet 361, 2189-2195, (2003).

- Demonstrates that once recurrent acute otitis media (AOM) is established in a child, pneumococcal conjugate vaccine may not be able to reduce further episodes of AOM.

54 Dagan R, Givon-Lavi N, Zamir O, Fraser $D$. Effect of a nonavalent conjugate vaccine on carriage of antibiotic-resistant Streptococcus pneumoniae in day-care centers. Pediatr. Infect. Dis. J. 22, 532-540 (2003).

55 Dagan R, Givon-Lavi N, Zamir O et al. Reduction of nasopharyngeal carriage of Streptococcus pneumoniae after administration of a 9-valent pneumococcal conjugate vaccine to toddlers attending day care centers. J. Infect. Dis. 185, 927-936 (2002).

56 Escola J, Kilpi T, Palmu A et al. Efficacy of a pneumococcal conjugate vaccine against acute otitis media. N. Engl. J. Med. 344, 403-409 (2001).

57 Porat N, Arguedas A, Spratt BG et al. Emergence of penicillin-nonsusceptible Streptococcus pneumoniae clones expressing serotypes not present in the antipneumococcal conjugate vaccine. J. Infect. Dis. 190, 2154-2161 (2004).

- Identifies the potential for capsular transformation to serve as a mechanism for spreading antibiotic resistance to nonvaccine serotypes.

58 Hanage WP, Auranen K, Syrjanen R et al. Ability of pneumococcal serotypes and clones to cause acute otitis media: implications for the prevention of otitis media by conjugate vaccines. Infect. Immun. 72, 76-81 (2004).

59 Bogaert D, van Belkum A, Sluijter M et al. Colonisation by Streptococcus pneumoniae and Staphylococcus aureus in healthy children. Lancet 363, 1871-1872 (2004).

60 Regev-Yochay G, Dagan R, Raz M et al. Association between carriage of Streptococcus pneumoniae and Staphylococcus aureus in children. JAMA 292, 716-720 (2004).

61 Shulman ST, Tanz RR. Streptococcal otitis media: from epidemiology to pathogenesis. Clin. Infect. Dis. 41, 42-44 (2005).

62 Segal N, Givon-Lavi N, Leibovitz E, Yagupsky P, Leiberman A, Dagan R. Acute otitis media caused by Streptococcus pyogenes in children. Clin. Infect. Dis. 41, 35-41 (2005).
63 Lim DJ, Hermansson A, Hellstrom SO et al. Recent advances in otitis media. 3 animal models; anatomy and pathology; pathogenesis; cell biology and genetics. Ann Otol. Rhinol. Laryngol. 194(Suppl.), 31-41 (2005).

64 Murphy TF, Bakaletz LO, Kyd JM, Watson B, Klein D. Vaccines for otitis media: proposals for overcoming obstacles to progress. Vaccine 23, 2696-2702 (2005).

65 Fernandez J, Levine OS, Sanchez J et al. Prevention of Haemophilus influenzae type b colonization by vaccination: correlation with serum anti-capsular IgG concentration. J. Infect. Dis. 182, 1553-1556 (2000).

66 Heikkinen T, Ruuskanen O, Waris M, Ziegler T, Arola M, Halonen P. Influenza vaccination in the prevention of acute otitis media in children. Am. J. Dis. Child. 145, 445-448 (1991).

67 Clements DA, Langdon L, Bland C, Walter E. Influenza A vaccine decreases the incidence of otitis media in 6- to 30 month-old children in day care. Arch. Pediatr. Adolesc. Med. 149, 1113-1117 (1995).

68 Belshe RB, Mendelman PM, Treanor J et al. The efficacy of live attenuated, coldadapted, trivalent, intranasal influenza virus vaccine in children. N. Engl. J. Med. 338, 1405-1412 (1998).

69 Hoberman A, Greenberg DP, Paradise JL et al. Effectiveness of inactivated influenza vaccine in preventing acute otitis media in young children. A randomized controlled trial. JAMA 290, 1608-1616 (2003).

70 Jefferson T, Smith S, Demicheli V, Harnden A, Rivetti A, Di Pietrantonj C. Assessment of the efficacy and effectiveness of influenza vaccines in healthy children: systematic review. Lancet 365, 773-780 (2005).

71 McCarthy MW, Kockler DR. Trivalent intranasal influenza vaccine, live. Ann. Pharmacother. 38, 2086-2093 (2004).

72 Bergen R, Black S, Shinefield H et al. Safety of cold-adapted live attenuated influenza vaccine in a large cohort of children and adolescents. Pediatr. Infect. Dis. J. 23, 138-144 (2004).

73 Marchisio P, Cavagna R, Maspes B et al. Efficacy of intranasal virosomal influenza vaccine in the prevention of recurrent acute otitis media in children. Clinical Infect. Dis. 35, 168-174 (2002).

74 Kim HW, Canchola JG, Brandt CD et al. Respiratory syncytial virus disease in infants despite prior administration of antigenic inactivated vaccine. Am. J. Epidemiol. 89, 422-434 (1969).
75 Maggon K, Barik S. New drugs and treatment for respiratory syncytial virus. Rev. Med. Virol. 14, 149-168 (2004).

76 Tristram DA, Welliver RC, Mohar CK, Hogerman DA, Hildreth SW, Paradiso P. Immunogenicity and safety of respiratory syncytial virus subunit vaccine in seropositive children 18-36 months old. J. Infect. Dis. 167, 191-195 (1993).

77 Paradiso PR, Hildreth SW, Hogerman DA et al. Safety and immunogenicity of a subunit respiratory syncytial virus vaccine in children 24 to 48 months old. Pediatr. Infect. Dis. J. 13, 792-798 (1994).

78 Piedra PA, Cron SG, Jewell A et al. Immunogenicity of a new purified fusion protein vaccine to respiratory syncytial virus: a multi-center trial in children with cystic fibrosis. Vaccine 21, 2448-2460 (2003).

Munoz FM, Piedra PA, Glezen WP. Safety and immunogenicity of respiratory syncytial virus purified fusion protein-2 vaccine in pregnant women. Vaccine 21 , 3465-3467 (2003).

- Demonstrates that maternal immunization with the respiratory syncytial virus (RSV) subunit vaccine, PFP-2, induces a vaccine specific response that is transferred transplacentally and also present in breast milk.

80 Mejias A, Chavez-Bueno S, Rios AM et al. Comparative effects of two neutralizing anti-respiratory syncytial virus (RSV) monoclonal antibodies in the RSV murine model: time versus potency. Antimicrob. Agents. Chemother. 49, 4700-4707 (2005).

81 Karron RA, Wright PF, Crowe JE Jr et al. Evaluation of two live, cold passaged, temperature-sensitive respiratory syncytial virus vaccines in chimpanzees, and in human adults, infants and children. J. Infect. Dis. 176, 1428-1436 (1997).

82 Wright PF, Karron RA, Belshe RB et al. Evaluation of a live, cold-passaged, temperature sensitive, respiratory syncytial virus vaccine candidate in infancy. J. Infect. Dis. 182, 1331-1342 (2000).

83 Karron RA, Wright PF, Belshe RB et al. Identification of a recombinant live attenuated respiratory syncytial virus vaccine candidate that is highly attenuated in infants. J. Infect. Dis. 191, 1093-1104 (2005).

- Demonstrates the safety and immunicity of a live-recombinant RSV vaccine in infants.

84 Belshe RB, Newman FK, Anderson EL et al. Evaluation of combined live, attenuated respiratory syncytial virus and 
parainfluenza 3 virus vaccines in infants and young children. J. Infect. Dis. 190, 2096-2103 (2004).

85 Gitiban N, Jurcisek JA, Harris RH et al. Chinchilla and murine models of upper respiratory tract infections with respiratory syncytial virus. J. Virol. 79, 6035-6042 (2005).

86 Karron RA, Belshe RB, Wright et al. A live human parainfluenza type 3 virus vaccine is attenuated and immunogenic in young infants. Pediatr. Infect. Dis. J. 22, 394-405 (2003).

87 Belshe RB, Newman K, Tsai TF et al. Phase 2 evaluation of parainfluenza type 3 cold passage mutant 45 live attenuated vaccine in healthy children 6-18 months old. J. Infect. Dis. 189, 462-470 (2004).

88 Prevention of pneumococcal disease: recommendations of the Advisory Committee on Immunization Practices (ACIP). MMWR 46, 1-24 (1997).

89 Hausdorff WP, Bryant J, Paradiso PR, Siber GR. Which pneumococcal serogroups cause the most invasive disease: implications for conjugate vaccine formulation and use, Part I. Clin. Infect. Dis. 30, 100-121 (2000).

90 Hausdorff WP, Bryant J, Kloek C, Paradiso PR, Siber GR. The contribution of specific pneumococcal serogroups to different disease manifestations: implications for conjugate vaccine formulation and use, Part II. Clin. Infect. Dis. 30, 122-140 (2000).

91 Pelton SI, Dagan R, Gaines BM et al. Pneumococcal conjugate vaccines: proceedings from an interactive symposium at the 41 st Interscience Conference on Antimicrobial Agents and Chemotherapy. Vaccine 21, 1562-1571 (2003).

92 McChlery SM, Scott KJ, Clarke SC. Clonal analysis of invasive pneumococcal isolates in Scotland and coverage of serotypes by the licensed conjugate polysaccharide pneumococcal vaccine: possible implications for UK vaccine policy. Eur. J. Clin. Microbiol. Infect. Dis. 24, 262-267 (2005).

93 Nurkka A, Ahman H, Korkeila M, Jantti V, Kayhty H, Eskola J. Serum and salivary anti-capsular antibodies in infants and children immunized with the heptavalent pneumococcal conjugate vaccine. Pediatr. Infect. Dis. J. 20, 25-33 (2001).

94 Nurkka A, Lahdenkari M, Palmu AA, Kayhty H; FinOM Study Group. Salivary antibodies induced by the seven-valent PncOMPC conjugate vaccine in the Finnish Otitis Media Vaccine Trial. BMC Infect. Dis. 5, 41 (2005).
95 Wuorimaa T, Dagan R, Vakevainen M et al. Avidity and subclasses of IgG after immunization of infants with an 11-valent pneumococcal conjugate vaccine with or without aluminum adjuvant. J. Infect. Dis. 184, 1211-1215 (2001).

96 Vidarsson G, Sigurdardottir ST, Gudnason $T$ et al. Isotypes and opsonophagocytosis of pneumococcus type $6 \mathrm{~B}$ antibodies elicited in infants and adults by an experimental pneumococcus type 6Btetanus toxoid vaccine. Infect. Immun. 66, 2866-2870 (1998).

97 Bogaert D, Veenhoven RH, Ramdin R et al. Pneumococcal conjugate vaccination does not induce a persisting mucosal IgA response in children with recurrent acute otitis media. Vaccine 23, 2607-2613 (2005).

98 Korkeila M, Lehtonen H, Ahman H, Leroy O, Eskola J, Kayhty H. Salivary anticapsular antibodies in infants and children immunised with Streptococcus pneumoniae capsular polysaccharides conjugated to diphtheria or tetanus toxoid. Vaccine 1 $8,1218-1226$ (2000).

99 Choo S, Zhang Q, Seymour L, Akhtar S, Finn A. Primary and booster salivary antibody responses to a 7 -valent pneumococcal conjugate vaccine in infants. J. Infect. Dis. 182, 1260-1263 (2000).

100 Nurkka A, Lahdenkari M, Palmu A, Kayhty H; FinOM Study Group. Salivary antibodies induced by the seven-valent PncCRM conjugate vaccine in the Finnish Otitis Media Vaccine Trial. Vaccine 23, 298-304 (2004).

101 Dagan R, Givon-Lavi N, Fraser D, Lipsitch M, Siber GR, Kohberger R. Serum serotype-specific pneumococcal anticapsular immunoglobulin IgG concentrations after immunization with a 9valent conjugate pneumococcal vaccine correlate with nasopharyngeal acquisition of pneumococcus. J. Infect. Dis. 192, 367-376 (2005).

102 Dagan R, Melamed R, Muallem M et al. Reduction of nasopharyngeal carriage of pneumococci during the second year of life by a heptavalent conjugate pneumococcal vaccine. J. Infect. Dis. 174, 1271-1278 (1996).

103 Dagan R, Muallem M, Melamed R, Leroy $\mathrm{O}$, Yagupsky P. Reduction of pneumococcal nasopharyngeal carriage in early infancy after immunization with tetravalent pneumococcal vaccines conjugated to either tetanus toxoid or diphtheria toxoid. Pediatr. Infect. Dis. J. 16, 1060-1064 (1997).

104 Black S, Shinefield H, Baxter R et al. Postlicensure surveillance for pneumococcal invasive disease after use of heptavalent pneumococcal conjugate vaccine in Northern California Kaiser Permanente. Pediatr. Infect. Dis. J. 23, 485-489 (2004).

105 Fireman B, Black SB, Shinefield HR et al. Impact of the pneumococcal conjugated vaccine on otitis media. Pediatr. Infect. Dis. J. 22, 10-16 (2003).

106 Black S, Shinefield H, Fireman B et al. Efficacy, safety and immunogenicity of heptavalent pneumococcal conjugate vaccine in children. Pediatr. Infect. Dis. J. 19, 187-195 (2000).

107 van Kempen MJ, Vermeiren JS, Vaneechoutte $\mathrm{M}$ et al. Pneumococcal conjugate vaccination in children with recurrent acute otitis media: a therapeutic alternative? Int. J. Pediatr. Otorhinolaryngol. 70, 275-285 (2006).

108 van Heerbeek N, Straetemans M, Wiertsema SP et al. Effect of combined pneumococcal conjugate and polysaccharide vaccination on recurrent otitis media with effusion. Pediatrics 117, 603-608 (2006).

109 Dagan R, Sikular-Cohen M, Zamir O, Janco J, Givon-Levi N, Fraser D. Effect of a conjugate pneumococcal vaccine on the occurrence of respiratory disease infections and antibiotic use in day-care center attendees. Pediatr. Infect. Dis. J. 20, 951-958 (2001).

110 Dagan R, Kayhty H, Wuorimaa T et al. Tolerability and immunogenicity of an eleven valent mixed carrier Streptococcus pneumoniae capsular polysaccharide-diphtheria toxoid or tetanus protein conjugate vaccine in Finnish and Israeli infants. Pediatr. Infect. Dis. J. 23, 91-98 (2004).

111 Puumalainen T, Zeta-Capeding MR, Kayhty $\mathrm{H}$ et al. Antibody response to an eleven valent diphtheria- and tetanus-conjugated pneumococcal conjugate vaccine in Filipino infants. Pediatr. Infect. Dis. J. 21, 309-314 (2002).

112 Nurkka A, Joensuu, J, Henckaerts I, et al. Immunogenicity and safety of the eleven valent pneumococcal polysaccharide-protein $\mathrm{D}$ conjugate vaccine in infants. Pediatr. Infect. Dis. J. 11, 1008-1014 (2004).

113 Prymula R, Peeters P, Chrobok V et al. Pneumococcal capsular polysaccharides conjugated to protein $\mathrm{D}$ for prevention of acute otitis media caused by both Streptococcus pneumoniae and non-typable Haemophilus influenzae: A randomised double-blind efficacy study. Lancet 367, 740-748 (2006).

-. Demonstrates for the first time that a pneumococcal vaccine conjugated to $H$. influenzae-derived protein $\mathrm{D}$ provides a moderate amount of protection against AOM caused by both vaccine and 
nonvaccine pneumococcal serotypes, as well as nontypeable Haemophilus influenzae (NTHi).

114 Giebink GS, Meier JD, Quartey MK, Liebeler CL, Le CT. Immunogenicity and efficacy of Streptococcus pneumoniae polysaccharide-protein conjugate vaccines against homologous and heterologous serotypes in the chinchilla otitis media model. J. Infect. Dis. 173, 119-127 (1996).

115 Jokinen JT, Ahman H, Kilpi TM, Makela PH, Kayhty MH. Concentration of antipneumococcal antibodies as a serological correlate of protection: an application to acute otitis media. J. Infect. Dis. 190, 545-550 (2004).

116 Chaithongwongwatthana S, Yamasmit W, Limpongsanurak S et al. Pneumococcal vaccination during pregnancy for preventing infant infection. Cochrane Database Syst. Rev. (2006).

117 Hajek DM, Quartey M, Giebink GS. Maternal pneumococcal conjugate immunization protects infant chinchillas in the pneumococcal otitis media model. Acta Otolaryngol. 122, 262-269 (2002).

118 White P, Hermansson A, Svanborg C, Briles D, Prellner K. Effects of active immunization with a pneumococcal surface protein (PspA) and of locally applied antibodies in experimental otitis media. ORL J. Otorhinolaryngol. Relat. Spec. 61, 206-211 (1999).

119 Briles DE, Hollingshead SK, King J et al. Immunization of humans with recombinant pneumococcal surface protein A ( $\mathrm{rPspA}$ ) elicits antibodies that passively protect mice from fatal infection with Streptococcus pneumoniae bearing heterologous PspA. J. Infect. Dis. 182, 1694-1701 (2000).

120 Briles DE, Ades E, Paton JC et al. Intranasal immunization of mice with a mixture of the pneumococcal proteins PsaA and PspA is highly protective against nasopharyngeal carriage of Streptococcus pneumoniae. Infect. Immun. 68, 796-800 (2000).

121 Ogunniyi AD, Folland RL, Briles DE, Hollingshead SK, Paton JC. Immunization of mice with combinations of pneumococcal virulence proteins elicits enhanced protection against challenge with Streptococcus pneumoniae. Infect. Immun. 68, 3028-3033 (2000).

-. Demonstrates that immunization with a combination of PspA, PsaA and PdB proteins provides a highly effective protective response against Streptococcus pneumoniae in an animal model.
122 Long JP, Tong HH, deMaria TF. Immunization with native or recombinant Streptococcus pneumoniae neuraminidase affords protection in the chinchilla otitis media model. Infect. Imm. 72, 4309-4313 (2004)

123 Hamel J, Charland N, Pineau I et al. Prevention of pneumococcal disease in mice immunized with conserved surface-accessible proteins. Infect. Imm. 72, 2659-2670 (2004).

124 Ueyama T, Gu XX, Tsai CM, Karpas AB, Lim DJ. Identification of common lipooligosaccharide types of isolates from patients with otitis media by monoclonal antibodies against nontypeable Haemophilus influenzae 9274. Clin. Diagn. Lab. Immunol. 6, 96-100 (1999).

125 McGhee JL, Radolf JD, Toews GB, Hansen EJ. Effect of primary immunization on pulmonary clearance of nontypeable Haemophilus influenzae. Am. J. Respir. Cell. Mol. Biol. 1, 201-210 (1989).

126 Rahman MM, Gu XX, Tsai CM, Kolli VS, Carlison RW. The structural heterogeneity of the lipooligosaccharide (LOS) expressed by pathogenic nontypeable Haemophilus influenzae strain NTHi 9274. Glycobiology 9, 1371-1380 (1999).

127 Gu XX, Tsai CM, Ueyama T, Barenkamp SJ, Robbins JB, Lim DJ. Synthesis, characterization and immunological properties of detoxified lipooligosaccharide from nontypeable Haemophilus influenzae conjugated to proteins. Infect. Immun. 64, 4047-4053 (1996).

$128 \mathrm{Gu}$ XX, Sun J, Jin S et al. Detoxified lipooligosaccharide from nontypeable Haemophilus influenzae conjugated to proteins confers protection against otitis media in chinchillas. Infect. Immun. 65, 4488-4493 (1997).

129 Hirano T, Hou Y, Jia X, Gu XX. Intranasal immunization with a lipooligosaccharidebased conjugate vaccine from nontypeable Haemophilus influenzae enhances bacterial clearance in mouse nasopharynx. FEMS Immunol. Med. Microbiol. 35, 1-10 (2003)

130 Gu XX, Rudy SF, Chu C et al. Phase I study of a lipooligosaccharide-based conjugate vaccine against nontypeable Haemophilus influenzae. Vaccine 21, 2107-2114 (2003).

- Demonstrates that an NTHi dLOS-TT vaccine is well tolerated in adults.

131 Kyd JM, Dunkley ML, Cripps AW. Enhanced respiratory clearance of nontypeable Haemophilus influenzae following mucosal immunization with P6 in a rat model. Infect. Immun. 63, 2931-2940 (1995).
132 McMahon M, Murphy TF, Kyd J,

Thanavala Y. Role of an immunodominant $\mathrm{T}$ cell epitope of the P6 protein of nontypeable Haemophilus influenzae in murine protective immunity. Vaccine 23 , 3590-3596 (2005)

133 DeMaria TF, Murwin DM, Leake ER. Immunization with outer membrane P6 from nontypeable Haemophilus influenzae induces bactericidal antibody and affords protection in the chinchilla model of otitis media. Infect. Immun. 64, 5187-5192 (1996).

134 Sabirov A, Kodama S, Hirano T, Suzuki M, Mogi G. Intranasal immunization enhances clearance of nontypeable Haemophilus influenzae and reduces stimulation of tumor necrosis factor $\alpha$ production in the murine model of otitis media. Infect. Immun. 69, 2964-2971 (2001).

135 Bertot GM, Becker PD, Guzman CA, Grinstein $S$. Intranasal vaccination with recombinant $\mathrm{P} 6$ protein and adamantylamide dipeptide as mucosal adjuvant confers protection against otitis media and lung infection by nontypeable Haemophilus influenzae. J. Infect. Dis. 189, 1304-1312 (2004).

136 Sabirov A, Kodama S, Sabirova N, Mogi G, Suzuki M. Intranasal immunization with outer membrane protein P6 and cholera toxin induces specific sinus mucosal immunity and enhances sinus clearance of nontypeable Haemophilus influenzae. Vaccine 22, 3112-3121 (2004).

137 Yamauchi K, Hotomi M, Billal DS, Suzumoto M, Yamanaka N. Maternal intranasal immunization with outer membrane protein P6 maintains specific antibody level of derived offspring. Vaccine (In Press) (2006).

138 Kodama S, Suenaga S, Hirano T, Suzuki M, Mogi G. Induction of specific immunoglobulin A and Th2 immune responses to $\mathrm{P} 6$ outer membrane protein of nontypeable Haemophilus influenzae in middle ear mucosa by intranasal immunization. Infect. Immun. 68, 2294-2300 (2000).

139 Kyd JM, Cripps AW, Novotny LA, Bakaletz LO. Efficacy of the 26-dalton outer membrane protein and two P5 fimbrin-derived immunogens to induce clearance of nontypeable Haemophilus influenzae from the rat middle ear and lungs as well as from the chinchilla middle ear and nasopharynx. Infect. Immun. 71, 4691-4699 (2003). 
-. Demonstrates that OMP26 and P5 fimbrin-derived immunogens can induce a highly specific protective response in the rat and chinchilla OM models.

140 Kyd JM, Cripps AW. Potential of a novel protein, OMP 26, from nontypeable Haemophilus influenzae to enhance pulmonary clearance in a rat model. Infect. Immun. 66, 2272-2278 (1998).

141 Bakaletz LO, Kennedy BJ, Novotny LA, Duquesne G, Cohen J, Lobet Y. Protection against development of otitis media induced by nontypeable Haemophilus influenzae by both active and passive immunization in a chinchilla model of virus-bacterium superinfection. Infect. Immun. 67, 2746-2762 (1999).

142 Neary JM, Yi K, Karalus RJ, Murphy TF. Antibodies to loop 6 of the P2 porin protein of nontypeable Haemophilus influenzae are bactericidal against multiple strains. Infect. Immun. 69, 773-778 (2001).

143 Loosmore SM, Yang Y, Oomen R, Shortreed JM, Coleman DC, Klein MH. The Haemophilus influenzae HtrA protein is a protective antigen. Infect. Immun. 66, 899-906 (1998).

144 Winter LE, Barenkamp S. Human antibodies specific for highmolecular-weight adhesion proteins of Nontypeable Haemophilus influenzae mediate opsonophagocytic activity. Infect. Immun. 71, 6884-6891 (2003).

145 Cutter D, Mason KW, Howell AP, Fink DL, Green BA, St.Geme III JW. Immunization with Haemophilus influenzae Hap adhesin protects against nasopharyngeal colonization in experimental mice. J. Infect. Dis. 186, 1115-1121 (2002).

146 Liu D, Mason KW, Mastri M et al. The C-terminal fragment of the internal 110-kilodalton passenger domain of the Hap protein of nontypeable Haemophilus influenzae is a potential vaccine candidate. Infect. Immun. 72, 6961-6968 (2004).

147 Reilly TJ, Smith AL. Purification and characterization of a recombinant Haemophilus influenzae outer membrane phosphomonoesterase (P4). Protein Expr. Purif. 17, 401-409 (1999).

148 Green BA, Vazquez ME, Zlotnick GW et al. Evaluation of mixtures of purified Haemophilus influenzae outer membrane proteins in protection against challenge with nontypeable $H$. influenzae in the chinchilla otitis media model. Infect. Immun. 61, 1950-1957 (1993).
149 Hotomi M, Ikeda Y, Suzumoto K et al. A recombinant $\mathrm{P} 4$ protein of Haemophilus influenzae induces responses biologically active against nasopharyngeal colonization after intranasal immunization. Vaccine 23, 1294-1300 (2005).

150 Green BA, Baranyi E, Reilly TJ, Smith AL, Zlotnick GW. Certain site-directed, nonenzymatically active mutants of the Haemophilus influenzae P4 lipoprotein are able to elicit bactericidal antibody. Infect. Immun. 73, 4454-4457 (2005).

151 Chen D, Barniak V, Vandermeid KR, McMichael JC. The levels and bactericidal capacity of antibodies directed against the UspA1 and UspA2 outer membrane proteins of Moraxella (Branhamella) catarrhalis in adults and children. Infect. Immun. 67, 1310-1316 (1999).

152 Yang YP, Myers LE, McGuinness U et al. The major outer membrane protein, $\mathrm{CD}$, extracted from Moraxella (Branhamella) catarrhalis is a potential vaccine antigen that induces bactericidal antibodies. FEMS Immunol. Med. Microbiol. 17, 187-199 (1997).

153 Helminen ME, Maciver I, Latimer JL, Cope LD, McCracken GHJ, Hansen EJ.

A major outer membrane protein of Moraxella catarrhalis is a target for antibodies that enhance pulmonary clearance of the pathogen in an animal model. Infect. Immun. 61, 2003-2010 (1993).

154 Murphy TF, Kyd JM, John A, Kirkham C, Cripps AW. Enhancement of pulmonary clearance of Moraxella (Branhamella) catarrhalis following immunization with outer membrane protein $\mathrm{CD}$ in a mouse model. J. Infect. Dis. 178, 1667-1675 (1998).

$155 \mathrm{Yu}$ S, Gu XX. Synthesis and characterization of lipooligosaccharide-based conjugate vaccines for serotype B Moraxella catarrhalis. Infect. Immun. 73, 2790-2796 (2005).

156 Gu XX, Chen J, Barenkamp JB et al. Synthesis and characterization of lipooligosaccharide-based conjugates as vaccine candidates for Moraxella (Branhamella) catarrhalis. Infect. Immun. 66, 1891-1897 (1998).

157 Jiao X, Takashi H, Hou Y, Gu XX. Specific immune responses and enhancement of murine pulmonary clearance of Moraxella catarrhalis by intranasal immunization with a detoxified lipooligosaccharide conjugate vaccine. Infect. Immun. 70, 5982-5989 (2002).

158 Pai VB, Heyneman CA, Erramouspe J. Conjugated heptavalent pneumococcal vaccine. Ann. Pharmacotheraphy 36, 1403-1413 (2002).
159 Jodar L, Buttler J, Carlone G et al. Serological criteria for evaluation and licensure of new pneumococcal conjugate vaccine formulations. Vaccine 21, 3265-3272 (2003).

160 Lee LH, Frasch CE, Falk LA, Klein DL, Deal CD. Correlates of immunity for pneumococcal conjugate vaccines. Vaccine 21, 2190-2196 (2003).

\section{Websites}

201 Study of Streptococcus pneumoniae in nose and throats of infants with acute otitis media. ClinicalTrials.gov identifier NCT00195611.

http://clinicaltrials.gov/ct/gui/show/NCT0 0195611

202 The Jordan Report. 20 ${ }^{\text {th }}$ Anniversary. Accelerated Development of Vaccines 2002. www.niaid.nih.gov/dmid/vaccines/ jordan20/

203 MEDI-524 (Numax-TM) for prevention of respiratory syncytial virus (RSV) disease among native American Indian infants in the southwestern United States. www.clinical trials.gov/show/ NCT00121108

204 Study to evaluate the safety, tolerability, and immunogenicity of motavizumab (MEDI524) and palivizumab when administered in the same respiratory syncytial virus season.

www.clinicaltrials.gov/show/ NCT00316264

205 Neonatal immunization with pneumococcal conjugate vaccine in Papua New Guinea. ClinicalTrials.gov identifier NCT00219401.

http://clinicaltrials.gov/ct/gui/show/NCT0 0219401

206 Study evaluating pneumococcal vaccine in healthy infants. ClinicalTrials.gov identifier NCT00205803.

http://clinicaltrials.gov/ct/gui/show/NCT0 0205803

\section{Affiliations}

- Allan W Cripps, BSc (Hons) PhD Griffith University, School of Medicine, Gold Coast Campus, PMB 50 Gold Coast MC, QLD, 9726, Australia Tel.: +61756780709

Fax: +61756780795 allan.cripps@griffith.edu.au

- Diana C Otczyk, PhD Griffith University, School of Medicine, Gold Coast Campus, PMB 50 Gold Coast MC, QLD, 9726, Australia

Tel.: +61756780709

Fax: +61756780795

d.otczyk@griffith.edu.au 
Prospects for a vaccine against otitis media 